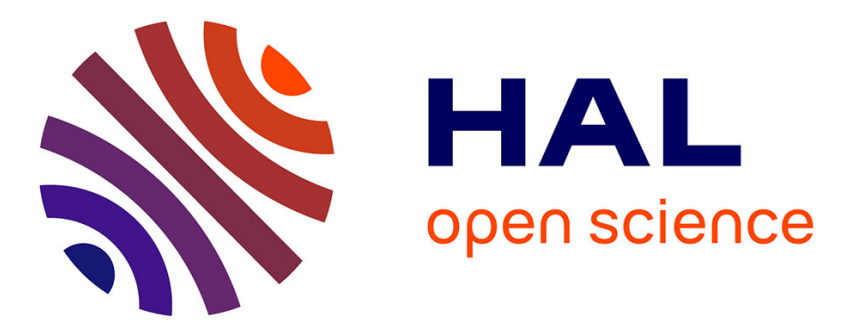

\title{
Detection of QTL controlling metabolism, meat quality, and liver quality traits of the overfed interspecific hybrid mule duck
}

\author{
M. Kileh-Wais, J M Elsen, A Vignal, K Feves, F Vignoles, Xavier Fernandez, \\ H Manse, Stéphane Davail, Jean-Marc André, Denis Bastianelli, et al.
}

\section{To cite this version:}

M. Kileh-Wais, J M Elsen, A Vignal, K Feves, F Vignoles, et al.. Detection of QTL controlling metabolism, meat quality, and liver quality traits of the overfed interspecific hybrid mule duck. Journal of Animal Science, 2013, 91 (2), pp.588-604. 10.2527/jas.2012-5411 . hal-01702555

\section{HAL Id: hal-01702555 \\ https://hal.science/hal-01702555}

Submitted on 6 Feb 2018

HAL is a multi-disciplinary open access archive for the deposit and dissemination of scientific research documents, whether they are published or not. The documents may come from teaching and research institutions in France or abroad, or from public or private research centers.
L'archive ouverte pluridisciplinaire HAL, est destinée au dépôt et à la diffusion de documents scientifiques de niveau recherche, publiés ou non, émanant des établissements d'enseignement et de recherche français ou étrangers, des laboratoires publics ou privés. 


\section{JOURNAL OF ANIMAL SCIENCE}

The Premier Journal and Leading Source of New Knowledge and Perspective in Animal Science

\section{Detection of QTL controlling metabolism, meat quality, and liver quality traits of the overfed interspecific hybrid mule duck}

M. Kileh-Wais, J. M. Elsen, A. Vignal, K. Feves, F. Vignoles, X. Fernandez, H. Manse, S. Davail, J. M. André, D. Bastianelli, L. Bonnal, O. Filangi, E. Baéza, D. Guéméné, C. Genêt, M. D. Bernadet, F. Dubos and C. Marie-Etancelin

J ANIM SCI 2013, 91:588-604.

doi: 10.2527/jas.2012-5411 originally published online November 12, 2012

The online version of this article, along with updated information and services, is located on the World Wide Web at:

http://www.journalofanimalscience.org/content/91/2/588

www.asas.org 


\title{
Detection of QTL controlling metabolism, meat quality, and liver quality traits of the overfed interspecific hybrid mule duck ${ }^{1}$
}

\author{
M. Kileh-Wais,* J. M. Elsen,* A. Vignal, $\dagger$ K. Feves, $\uparrow$ F. Vignoles, $\dagger$ \\ X. Fernandez,\$ H. Manse, \$ S. Davail,§ J. M. André,§ D. Bastianelli,\# L. Bonnal,\# O. Filangi,

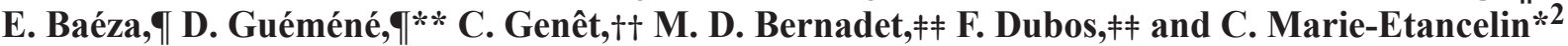 \\ *Institut National de la Recherche Agronomique, SAGA Station d'Amélioration Génétique des Animaux, UR631, 31326 \\ Castanet Tolosan, France; † Institut National de la Recherche Agronomique, LGC Laboratoire de Génétique Cellulaire, UR444, 31 \\ 326 Castanet Tolosan, France; \$Université de Toulouse, Institut National Polytechnique de Toulouse, Ecole Nationale Vétérinaire \\ de Toulouse, Ecole Nationale Supérieure Agronomique de Toulouse, Institut National de la Recherche Agronomique, TANDEM \\ Tissu Animaux, Nutrition, Digestion, Ecosystème et Métabolisme, UMR1289, 31326 Castanet Tolosan, France; §Université de \\ Pau et des Pays de l'Adour, IPREM-EMM Institut Pluridisciplinaire de recherche sur l'Environnement et les Matériaux, Equipe \\ Environnement et Microbiologie, UMR5254, 40004 Mont de Marsan Cedex, France; \#Centre de Coopération Internationale \\ en Recherche Agronomique pour le Développement, SELMET Systèmes d'Elevage Méditerranéens et Tropicaux, UR112, 34 \\ 398 Montpellier Cedex 5, France; || Institut National de la Recherche Agronomique, PEGASE Physiologie, Environnement et \\ Génétique pour l'Animal et les Systèmes d'Elevage, UMR1348, Agrocampus Ouest, 35000 Rennes, France; ๆInstitut National de \\ la Recherche Agronomique, URA Unité de Recherche Avicole, UR83, 37380 Nouzilly, France; **Syndicat des Sélectionneurs \\ Avicoles et Aquacoles Français SYSAAF, 37380 Nouzilly, France; ††Institut National de la Recherche Agronomique, GABI \\ Génétique Animale et Biologie Intégrative, UR1313, 78352 Jouy-en-Josas, France; and fキInstitut National de la Recherche \\ Agronomique, UEPFG Unité Expérimentale des Palmipèdes à Foie Gras, UE89, 40280 Benquet, France
}

\begin{abstract}
The mule duck, an interspecific hybrid obtained by crossing common duck (Anas platyrhynchos) females with Muscovy (Cairina moschata) drakes, is widely used for fatty liver production. The purpose of the present study was to detect and map single and pleiotropic QTL that segregate in the common duck species, and influence the expression of traits in their overfed mule duck offspring. To this end, we generated a common duck backcross (BC) population by crossing Kaiya and heavy Pekin experimental lines, which differ notably in regard to the BW and overfeeding ability of their mule progeny. The $\mathrm{BC}$ females were mated to Muscovy drakes and, on average, 4 male mule ducks hatched per BC female (1600 in total) and were measured for growth, metabolism during growth and the overfeeding period, overfeeding ability, and the quality of their breast meat and fatty liver. The phenotypic value of $\mathrm{BC}$ females was estimated for each trait by assigning to each female the mean value of the phenotypes of her offspring. Estimations allowed for variance, which depended on the number of male offspring per $\mathrm{BC}$ and the heritability of the trait considered. The genetic map used for QTL detection consisted of 91
\end{abstract}

microsatellite markers aggregated into 16 linkage groups (LG) covering a total of $778 \mathrm{cM}$. Twenty-two QTL were found to be significant at the $1 \%$ chromosome-wide threshold level using the single-trait detection option of the QTLMap software. Most of the QTL detected were related to the quality of breast meat and fatty liver: QTL for meat $\mathrm{pH} 20$ min post mortem were mapped to LG4 (at the $1 \%$ genome-wide significance level), and QTL for meat lipid content and cooking losses were mapped to LG2a. The QTL related to fatty liver weight and liver protein and lipid content were for the most part detected on LG2c and LG9. Multitrait analysis highlighted the pleiotropic effects of QTL in these chromosome regions. Apart from the strong QTL for plasma triglyceride content at the end of the overfeeding period mapped to chromosome $\mathrm{Z}$ using single-trait analysis, all metabolic trait QTL were detected with the multitrait approach: the QTL mapped to LG14 and LG21 affected the plasma cholesterol and triglyceride contents, whereas the QTL mapped to LG2a seemed to impact glycemia and the basal plasma corticosterone content. A greater density genetic map will be needed to further fine map the QTL.

Key words: hybrid mule duck, liver quality, meat quality, metabolic trait, pleiotropy, quantitative trait loci

(C) 2013 American Society of Animal Science. All rights reserved.

J. Anim. Sci. 2013.91:588-604 doi:10.2527/jas2012-5411

\footnotetext{
${ }^{1}$ This work was supported by the French National Research Agency (GENANIMAL program), by the Scientific Group for avian genome analysis (AGENAVI), and the Midi-Pyrénées and Aquitaine regional councils. M. Kileh Wais was supported by a grant from INRAAnimal Genetics Division and the University of Djibouti. We particularly thank
}

the technicians of the UEPFG Experimental Unit who reared the ducks, recorded phenotypic traits, and performed blood sampling. We also thank G. Cardinet for her help developing the microsatellite markers.

${ }^{2}$ Corresponding author: Christel.Marie-Etancelin@toulouse.inra.fr Received April 24, 2012. Accepted October 26, 2012. 


\section{INTRODUCTION}

Ninety-five percent of the fatty liver production in France comes from mule ducks, the infertile interspecific hybrid progeny of common duck (Anas platyrhynchos) females and Muscovy (Cairina moschata) drakes. Genetic improvement of mule duck performances is thus achieved by selecting both parental species for production traits, which are then recorded in their progenies. The parental lines are usually selected for specific traits. Muscovy ducks are mainly selected for their BW and feed efficiency, whereas genetic improvement in common ducks focuses on reproductive traits (Marie-Etancelin et al., 2008). Therefore, the breeding values of purebred reproducer duck candidates are assessed by progeny testing, lengthening the generation interval. Moreover, the measurement of the traits related to the quality of the products is expensive and ruins the end products. In this context, it is particularly interesting to identify major genes or QTL in the parental populations that have an impact on traits in the mule duck. To investigate QTL that segregate in the common duck, an experimental backcross (BC) using 2 experimental lines was designed. The phenotypic value of these $\mathrm{BC}$ females was estimated by averaging the performances recorded for their mule duck offspring. The QTL measured in this way were then mapped by genotyping the $\mathrm{BC}$ females with microsatellites markers.

The primary objective of the present study was to identify chromosomal regions influencing production traits, mainly traits related to the quality of fatty liver and breast muscle in overfed mule ducks. However, to dissect the underlying physiological mechanisms, metabolic traits related to lipid metabolism during overfeeding were also investigated. A first round of QTL detection were performed on a trait by trait basis, after which multitrait analyses were performed, for all co-localized QTL and all correlated traits, to identify pleiotropic or linked QTL.

\section{MATERIALS AND METHODS}

Experimental procedures were performed in accordance with French National Guidelines for the care and use of animals for research purposes (Certificate of Authorization to Experiment on Living Animals No. 7740, Ministry of Agriculture and Fish Products).

\section{Animals and Husbandry}

The experimental design, a grandson design with male mule ducks measured to estimate the value of their mothers, is similar in principle to the granddaughter design proposed for dairy cows (Weller et al., 1990), and includes 4 generations (Fig. 1). Great-grandparents (Generation 0) were recruited in 2 experimental strains of the common duck: I444, a light Kaiya strain (the crossbreeding product of a Tsaiya duck and an Asian Pekin duck) and I37, a heavy Pekin strain (a synthetic strain created from 3 heavy European Pekin lines). The choice of this cross was motivated by the results described by Rouvier et al. (1994) showing that the growth and fatty liver performances in the male mule duck offspring of Tsaiya ducks, of Pekin ducks, or of their crossbreds were significantly different. Seven grandson families were produced, in which the grandsires (Generation 1) were therefore 7 (I444 $\times$ I37) $\mathrm{F} 1$ individuals, crossed to a total of 64 common female I444 ducks, to produce a total of 382 BC females (Generation 2). The $7 \mathrm{~F} 1$ drakes have no parent in common, and only 2 drakes shared a common maternal grand sire. Finally, all BC females were mated by AI to a single Muscovy drake, and produced a final population of 1600 mule ducks (Generation 3), which was used to estimate the $\mathrm{BC}$ phenotypic values. However, the number of mule duck progenies per BC female was highly variable, ranging from 1 to 8 , with $85 \%$ of the $\mathrm{BC}$ females having 3 or more mule duck progenies. In this experiment, all phenotypic measurements were recorded on mule ducks.

As described by Marie-Etancelin et al. (2011), mule ducklings belonging to a same hatching batch were bred in 8 growing batches of 50 animals from 0 to $12 \mathrm{wk}$ of age. At 12 wk of age, 2 successive series of 200 animals were overfed for a period of $12 \mathrm{~d}$. The 2 series were started at a 2-d interval, starting respectively at 80 and $82 \mathrm{~d}$ of age. Both overfeeding series consisted of the combination of 4 growing batches, and the actual overfeeding of each series was performed by 2 different crammers. So, if the hatching batch, overfeeding series, and growing batch effects were successively nested, the crammer effect was merged with the overfeeding series

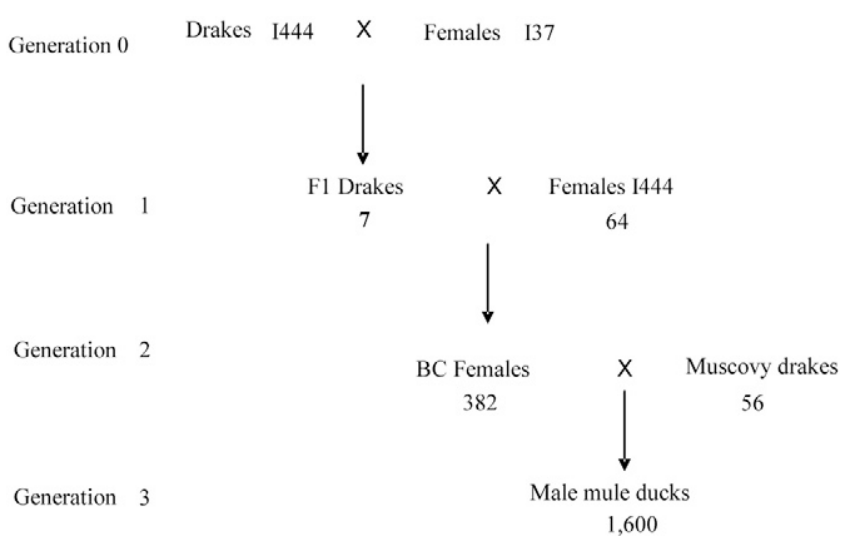

Figure 1. Experimental design consists of a backcross (BC) design from 2 experimental strains of common ducks: the I444 strain (a light Kaiya strain) and the $\mathrm{I} 37$ strain (a heavy Pekin strain). 
effect. At the end of the overfeeding period, the animals were slaughtered at 92 and $94 \mathrm{~d}$ of age, respectively. To avoid confounding between a group of full-sib mule ducks (progeny of a BC dam) and fixed effects, mule ducks were separated into the 2 annual hatching series, then into different growing batches and overfeeding series. For each animal, the hatching, growing, and overfeeding batches were recorded. The zootechnical schedule of the mule ducks is detailed in Appendix 1.

Measurements recorded for mule ducks are detailed in Table 1, and divided into 6 types of traits: growth traits before the overfeeding period, corticosterone traits,

Table 1. Trait abbreviations, descriptions, means, and $\mathrm{SD}$ ( $n$ ranging from 340 to 342 )

\begin{tabular}{|c|c|c|c|}
\hline Trait & & Means & SD \\
\hline \multicolumn{4}{|l|}{ Growth measurements } \\
\hline BW12, kg & BW (at $12,28,42,70 \mathrm{~d}$ of age) & 0.34 & 0.06 \\
\hline BW28, kg & & 1.37 & 0.13 \\
\hline $\mathrm{BW} 42, \mathrm{~kg}$ & & 2.31 & 0.16 \\
\hline $\mathrm{BW} 70, \mathrm{~kg}$ & & 3.40 & 0.21 \\
\hline BWG12-28, g/d & BW gain & 60.92 & 4.58 \\
\hline BWG12-42, g/d & & 63.49 & 4.17 \\
\hline BWG12-70, g/d & & 51.84 & 3.07 \\
\hline BWG28-42, g/d & & 62.11 & 4.82 \\
\hline BWG28-70, g/d & & 47.04 & 3.48 \\
\hline BWG42-70, g/d & & 37.64 & 4.36 \\
\hline $\mathrm{BW}_{\mathrm{A}}, \mathrm{kg}$ & Asymptotic BW & 4.07 & 0.25 \\
\hline $\mathrm{T}_{\mathrm{i}}, \mathrm{d}$ & Age at inflection point & 23.51 & 1.60 \\
\hline \multicolumn{4}{|l|}{ Corticosterone traits } \\
\hline CortL, $\mathrm{ng} / \mathrm{mL}$ & $\begin{array}{l}\text { Corticosterone concentration } \\
\text { before stress }\end{array}$ & 9.77 & 5.80 \\
\hline CortH, ng/mL & $\begin{array}{l}\text { Corticosterone concentration } \\
\text { after stress }\end{array}$ & 55.95 & 28.16 \\
\hline DeltaC, ng/mL & $\begin{array}{l}\text { Corticosterone difference } \\
\text { between before and after stress }\end{array}$ & 46.18 & 26.27 \\
\hline \multicolumn{4}{|c|}{ BW and metabolic traits during overfeeding period } \\
\hline DFI, $\mathrm{kg} / \mathrm{d}$ & DFI & 1.32 & 0.04 \\
\hline BWbeg, kg & $\begin{array}{l}\text { BW at beginning of } \\
\text { overfeeding period }\end{array}$ & 3.83 & 0.22 \\
\hline BWend, $\mathrm{kg}$ & $\begin{array}{l}\text { BW at end of overfeeding } \\
\text { period }\end{array}$ & 5.80 & 0.25 \\
\hline OWG, $\mathrm{kg}$ & $\begin{array}{l}\text { Weight gain during the } \\
\text { overfeeding period }\end{array}$ & 1.97 & 0.15 \\
\hline TG 2ndM, g/L & \multirow{3}{*}{$\begin{array}{l}\text { Plasma triglyceride content (at } \\
\text { second, 10th and 20th meal) }\end{array}$} & 4.30 & 0.64 \\
\hline TG 10thM, g/L & & 4.60 & 0.65 \\
\hline TG 20thM, g/L & & 4.90 & 0.88 \\
\hline CHO 2ndM, g/L & \multirow{3}{*}{$\begin{array}{l}\text { Plasma cholesterol content (at } \\
\text { second, 10th and 20th meal) }\end{array}$} & 1.71 & 0.14 \\
\hline CHO 10thM, g/L & & 2.11 & 0.19 \\
\hline CHO 20thM, g/L & & 2.46 & 0.30 \\
\hline GLU 2ndM, g/L & \multirow{3}{*}{$\begin{array}{l}\text { Plasma glucose content (at } \\
\text { second, 10th and 20th meal) }\end{array}$} & 2.21 & 0.15 \\
\hline GLU 10thM, g/L & & 2.69 & 0.29 \\
\hline GLU 20th M, g/L & & 3.12 & 0.67 \\
\hline $\mathrm{FC} 2 \mathrm{ndM}^{1}$ & \multirow{3}{*}{$\begin{array}{l}\text { Catching ease (at second, 10th } \\
\text { and 20th meal) }\end{array}$} & 2.55 & 0.60 \\
\hline FC 10 thM $^{1}$ & & 2.57 & 0.64 \\
\hline FC 20 thM $^{1}$ & & 2.53 & 0.65 \\
\hline
\end{tabular}

BW and metabolic traits during the overfeeding period, overfeeding ability traits measured after slaughter, liver quality traits, and muscle quality traits. Body weights were recorded at $12,28,42$, and $70 \mathrm{~d}$ of age. A hanging test, measuring the stress response of the animal, was performed at 6 wk of age: ducks were hung by the legs on a string for $10 \mathrm{~min}$, and blood samples (vacutainer of $3 \mathrm{~mL}$ with heparin; separation of plasma by centrifugation and kept at $-20^{\circ} \mathrm{C}$ ) were taken before and after the test to estimate the corticosterone concentrations and to assess the response of the hypothalamic-pituitary-adrenal axis to this hanging stress. Plasma metabolite concentrations

Table 1. (cont.)

\begin{tabular}{|c|c|c|c|}
\hline Trait & & Means & $\mathrm{SD}$ \\
\hline FO 2ndM ${ }^{1}$ & \multirow{3}{*}{$\begin{array}{l}\text { Overfeeding ease (at second, } \\
10 \text { th and } 20 \text { th meal) }\end{array}$} & 1.97 & 0.69 \\
\hline FO $10 \operatorname{thM}^{1}$ & & 1.31 & 0.36 \\
\hline FO $20 \operatorname{thM}^{1}$ & & 1.24 & 0.36 \\
\hline \multicolumn{4}{|c|}{ Overfeeding ability traits } \\
\hline $\mathrm{CW}, \mathrm{kg}$ & Bled-plucked carcass weight & 4.90 & 0.22 \\
\hline FLW, kg & Fatty liver weight & 0.57 & 0.07 \\
\hline pmMW, kg & $\begin{array}{l}\text { Pectoralis major muscle } \\
\text { weight }\end{array}$ & 0.26 & 0.02 \\
\hline pmSFW, $\mathrm{kg}$ & $\begin{array}{l}\text { Breast skin }+ \text { subcutaneous fat } \\
\text { weight }\end{array}$ & 0.15 & 0.01 \\
\hline TSW, kg & Thigh + shank weight & 0.48 & 0.03 \\
\hline $\mathrm{AFW}, \mathrm{kg}$ & Abdominal fat weight & 0.17 & 0.02 \\
\hline \multicolumn{4}{|c|}{ Liver quality traits } \\
\hline MR, \% & Liver melting rate & 38.67 & 8.56 \\
\hline $\mathrm{LL}^{*}$ & Liver lightness & 72.40 & 1.48 \\
\hline $\mathrm{La}^{*}$ & Liver redness & 9.19 & 1.16 \\
\hline $\mathrm{Lb}^{*}$ & Liver yellowness & 31.20 & 2.19 \\
\hline LLipC, \% & Liver lipid content & 52.37 & 2.72 \\
\hline LProtC, \% & Liver protein content & 7.69 & 0.48 \\
\hline LColC, mg/g & Liver collagen content & 1.27 & 0.16 \\
\hline $\mathrm{TFL}^{1}$ & Texture of fatty liver & 1.29 & 1.09 \\
\hline $\mathrm{ERS}^{1}$ & Extent of red spots & 1.11 & 0.43 \\
\hline $\mathrm{EG}^{1}$ & Type of grain & 0.95 & 0.54 \\
\hline $\mathrm{ESV}^{1}$ & $\begin{array}{l}\text { Extent of spots due to the } \\
\text { viscera }\end{array}$ & 1.45 & 0.52 \\
\hline $\mathrm{PL}^{1}$ & Lobes of pigmentation & 0.41 & 0.29 \\
\hline \multicolumn{4}{|c|}{ Muscle quality traits } \\
\hline Energy, $\mathrm{mJ}$ & $\begin{array}{l}\text { Energy needed to cut the } \\
\text { muscle }\end{array}$ & 149.58 & 26.37 \\
\hline Fmax & Maximal shear force & 42.37 & 5.13 \\
\hline ML* & Muscle lightness & 47.34 & 3.91 \\
\hline Ma* & Muscle redness & 20.38 & 2.39 \\
\hline $\mathrm{Mb}^{*}$ & Muscle yellowness & 7.64 & 1.00 \\
\hline $\mathrm{MpH} 20$ & Muscle $\mathrm{pH} 20$ min post mortem & 6.01 & 0.11 \\
\hline $\mathrm{MpHu}$ & Muscle ultimate $\mathrm{pH}$ & 5.72 & 0.07 \\
\hline MCookL, \% & Muscle cooking losses & 22.20 & 2.50 \\
\hline MvacL, \% & Muscle drip losses & 1.57 & 0.42 \\
\hline MWC, $\%$ & Muscle water content & 71.69 & 0.54 \\
\hline MLipC, \% & Muscle lipid content & 4.92 & 1.27 \\
\hline
\end{tabular}


(glucose, triglyceride, and cholesterol) were measured at the beginning (after the second meal), the middle (after the 10th meal), and the end (after the 20th meal) of the 12-d overfeeding period. Body weight at the beginning and the end of the overfeeding period and feed consumption during the whole overfeeding period were recorded. Behavioral information, such as the ease of catching and overfeeding, was also registered at the beginning, middle, and end of the overfeeding period. To appreciate the overfeeding ability of the ducks, the carcass and component pieces (fatty liver, thigh, breast skin, breast muscle, and abdominal fat) were dissected and weighed. Measurements related to liver quality, such as the melting rate, lipid, protein, and collagen contents, and the color $\left(\mathrm{L}^{*}, \mathrm{a}^{*}, \mathrm{~b}^{*}\right.$ coordinates in the CIELAB system), were recorded. External liver traits (texture, pigmentation of lobes, necrosis area, and extent of red spots) were also assessed. Lastly, muscle quality was estimated by measuring the $\mathrm{pH} 20 \mathrm{~min}$ postmortem, the ultimate $\mathrm{pH}$, cooking losses, and drip losses under vacuum, descriptive color $\mathrm{L}^{*}, \mathrm{a}^{*}, \mathrm{~b}^{*}$ values, and by recording the lipid content. Raw meat tenderness was measured using the maximal shear force and energy levels for the Warner-Bratzler test. All meat quality measurements were performed on breast meat (Pectoralis major muscle). The genetic parameters of all these traits are detailed in MarieEtancelin et al. (2011).

\section{Genotyping and Map Construction}

Microsatellite markers were selected from 2 data sets: i) from 158 duck markers developed by the INRA-LGC laboratory (Marie-Etancelin et al., 2006; Supplementary Appendices 2 and 3; see online at http://journalofanimalscience.org) and ii) from the international nucleotide sequence data-bases (GenBank/ EMBL/DDBJ). To optimize the choice of the markers along the duck genome, we took advantage of the great similarity between duck and chicken karyotypes: all duck marker nucleotide sequences were located by sequence similarity in the chicken genome to predict their positions in the duck genome. The blast e-value cutoff for first-pass mapping of duck microsatellites on a chicken chromosome was $1 \mathrm{e}^{-4}$; for more precise location of markers included in duck genetic linkage groups (LG) already assigned to a chicken chromosome, the value was set to $1 \mathrm{e}^{-15}$.

One hundred and sixteen microsatellite markers were selected among the most informative (at least 3 of the $7 \mathrm{~F} 1$ sires heterozygous at the marker position) and well-distributed markers throughout the chicken genome. Markers were used to genotype the $\mathrm{BC}$ female ducks, their parents (sires F1 and dams I444), and their paternal grandparents. Fluorescent microsatellite analysis was performed on ABI3100 and ABI3730 DNA sequencers (Applied Biosystems, Foster City, CA). Data was analyzed using GeneMapper v. 4.0 software (Foster City, CA), and genotypes were entered in a local INRA database (GEMMA, LIMS) in which correct Mendelian inheritance could be checked. Linkage groups were built using the Crimap software 2.4 (Green et al., 1990).

\section{Statistical Methods}

Growth traits were modeled after the Weibull model according to Maruyama et al. (1999, 2001). The asymptotic weight $\left(\mathbf{B W}_{\mathbf{A}}\right)$ and the age at the inflection point $\left(\mathbf{t}_{\mathbf{i}}\right)$ of the growth curve were estimated with this model:

$$
\mathrm{BW}_{\mathrm{t}}=\mathrm{BW}_{\mathrm{A}}-\left(\mathrm{BW}_{\mathrm{A}}-B\right) \exp ^{\left[-1\left(\frac{C-1}{C}\right)\left(\frac{t}{t_{\mathrm{i}}}\right)^{c}\right]}
$$

where $\mathrm{BW}_{\mathrm{t}}$ is the $\mathrm{BW}$ at age $t, \mathrm{BW}_{\mathrm{A}}$ is the asymptotic weight, and $t_{\mathrm{i}}$ is the age at the inflection point. The parameters $B$ and $C$ have no biological interpretation. These parameters were estimated by nonlinear regression with the NLIN procedure (SAS Inst. Inc., Cary, NC) taking into account all available weights from birth to slaughter, at $12,28,42$, and $70 \mathrm{~d}$ of age.

Before performing the linkage analysis aimed at locating QTL, all mule duck traits (recorded and computed traits) were corrected for environmental fixed effects with a GLM procedure of SAS. For all traits, the hatching batch effect was taken into account, and either the growing batch effect, the overfeeding series effect, or the batch of measurement set effect was added for traits related to growth, overfeeding, or corticosterone, respectively. The residual effects of the previous linear model were conserved and the performance for each $\mathrm{BC}$ female was computed as the average of the residuals effects of her mule duck male offspring. A few traits (ease of catching, ease of overfeeding, liver texture, liver lobe pigmentation, or the extent of red spots) were not distributed on a continuous scale (Table 1), but were categorical data. Nevertheless, when mule duck residuals were averaged to be assigned to a given $\mathrm{BC}$ female, these traits could be considered as continuous. Thus, threshold traits were treated as normal traits.

Quantitative trait locus detection was performed with the QTLMap software (Elsen et al., 1999; Gilbert et al., 2008; Filangi et al., 2010) to implement linkage analysis according to the interval mapping method (Lander and Botstein, 1989). For each chromosome, the probabilities of each possible phase of the F1 male founders were first estimated using marker information from their progenies. The most likely sire phases were assumed to be correct: for a set of tested positions (practically every $1 \mathrm{cM}$ ), the probabilities for 
the transmission of the corresponding chromosomal segments to the offspring were estimated. Then, QTL detection was performed by within-sire linear regression (Knott et al., 1996). The model was the following:

$$
y_{i j}=s_{i}+\left(2 p_{i j}-1\right) a_{i}+e_{i j}
$$

where the dependent variable $y_{i j}$ is the average performance (previously corrected for fixed effects) of the $n_{i j}$ mule ducks male progenies of $\mathrm{BC} j$ and sire $i$. For each location on the genome, $s_{i}$ is the male founder $i$ effect, $a_{i}$ is half the substitution effect of the putative QTL carried by the sire $i$, and $p_{i j}$ is the probability that the daughter $(\mathrm{BC}) j$ might inherit 1 arbitrarily defined QTL allele from her sire $i$, given the marker information. The residual variance $e_{i j}$ was defined within sire families to improve robustness to unlinked QTL segregation between families (Goffinet et al., 1999).

In our grandson design with phenotypes recorded in only the third generation, the variance of the phenotypes assigned to the $\mathrm{BC}$ generation was expressed as

$$
\operatorname{var}\left(z_{j}\right)=\sigma^{2} \frac{1+\frac{1}{4}(n-1) h^{2}}{\frac{1}{4} n},
$$

with $\sigma^{2}=\sigma_{g}^{2}+\sigma_{e}^{2} ; n$ is the number of male offspring of $\mathrm{BC} ; \sigma_{g}^{2}, \sigma_{e}^{2}$, and $\sigma^{2}$ are the genetic, residual, and total variances, and $h^{2}=\sigma_{g}^{2} / \sigma^{2}$, the heritability of the trait (Kileh-Wais and Elsen, 2012). Those variances were computed with the Varcomp procedure of SAS software. For the multitrait approach, we took into account the covariance between traits $\mathrm{S}$ and $\mathrm{T}$ as

$$
\operatorname{cov}\left(z_{j}\right)=\frac{n_{\mathrm{ST}}+\frac{1}{4}\left(n_{\mathrm{S}} n_{\mathrm{T}}-n_{\mathrm{ST}}\right) \mathrm{r}_{\mathrm{ST}}}{n_{\mathrm{S}} n_{\mathrm{T}}} \operatorname{cov}(y),
$$

with $n_{\mathrm{S}}$ the number of male mule ducks, offspring of $\mathrm{BC} j$ for trait $\mathrm{S}, n_{\mathrm{T}}$ is the number for trait $\mathrm{T}, n_{\mathrm{ST}}$ is the number of male offspring of $\mathrm{BC} j$ for both traits $\mathrm{S}$ and $\mathrm{T}$, and $\mathrm{r}_{\mathrm{ST}}$ the ratio of genetic and phenotypic covariances between traits $\mathrm{S}$ and $\mathrm{T}$.

An adapted version of the QTLMap software (Elsen et al., 1999) was developed to take into account the heterogeneity of the phenotypic variance in single and in multitrait analyses (Filangi et al., 2010).

For each trait and each LG, 1000 withinfamily permutations were performed to estimate the empirical chromosome-wide significance level of the test statistics (Churchill and Doerge, 1994). The conservative genome-wide thresholds were derived from chromosome-wide significance levels, using an approximate Bonferroni correction:

$$
P_{\text {genome-wide }}=1-\left(1-P_{\text {chromosome-wide }}\right)^{1 / \mathrm{r}}
$$

where $r$ is the ratio between the length of a specific LG and the length of the genome considered for QTL detection $(778 \mathrm{cM})$. The $95 \%$ confidence intervals of the QTL locations were estimated by logarithm of odds (LOD) drop-off. In practice, the bounds of the interval were the 2 locations where the likelihood was equal to the maximum likelihood minus $3.84\left[=\chi_{(1,0.05)}^{2}\right]$. The QTL effect was expressed in phenotypic deviation units (SD), and estimated as

$$
\alpha=\frac{1}{\mathrm{SD}} \times \frac{1}{n} \sum_{i=1}^{n}\left|\alpha_{i}\right|,
$$

where SD is the phenotypic standard deviation and $n$ the number of sires (Roldan et al., 2010).

Quantitative trait locus detection was first performed on a single-trait basis. Because it has been shown previously that, in the case of linked or pleiotropic QTL (pIQTL), the use of simultaneous phenotypic information from different correlated traits increases the precision of QTL location and possibly the power of evidencing effects too small to be detected by single-trait analysis, multitrait QTL detection was also performed (Gilbert and Le Roy, 2003). Traits to be included in the multitrait analyses were grouped according to 2 main criteria: i) the co-location criteria (co-located QTL: CQ) for traits for which 2 or more significant QTL (at the $5 \%$ chromosome-wide threshold) were located in the same chromosomal area by single-trait approaches, and ii) the correlation criteria (Phenotypic Correlation: PC) for traits presenting phenotypic correlations greater than 0.55 (Supplementary Appendix 4; ; see online at http://journalofanimalscience.org). The CQ criteria is used to refine QTL location if the single-trait analyses indeed correspond to a single plQTL, whereas the PC criteria is used to detect new plQTL that could not be detected by the single-trait approach. Finally, as an additional phenotypic approach, metabolism traits during overfeeding were grouped by meal (2nd, 10th, or 20th meal) and component (cholesterol, triglyceride, and glucose) for multitrait QTL detection. Multitrait detection was performed by recursive backward approaches: among the $\mathrm{n}$ co-located or correlated traits for which a significant QTL was found, all sub-groups of traits ( 2 by 2, 3 by 3, etc.) were tested to identify the underlying linked or pleiotropic QTL. The most significant trait combinations, for which the $P$-value was lower than the lowest single-trait $P$-value, were retained and presented in the multitrait QTL Tables. 


\section{RESULTS}

\section{Genetic Maps}

A genetic map consisting of 91 markers aggregated into $16 \mathrm{LG}$ and covering a total of $778 \mathrm{cM}$ was obtained (Fig. 2). The sequence alignment by BLAST analysis of the duck microsatellite markers to the chicken genome sequence resulted in the assignment of the 16 duck LG to 13 different chicken chromosomes.

\section{Quantitative Trait Locus Detection}

Single-trait QTL analysis for all of the measured traits resulted in the detection of 74 QTL (Fig. 3). Of these, 22 were significant at the $1 \%$ chromosome-wide threshold. The results presented here focus on these most significant QTL, most of which are related to the overfeeding ability and product quality traits. The QTL are first presented as 3 groups of traits involved in agronomically related functions and for which physiological links can be speculated: growth; BW and metabolism during overfeeding; and overfeeding ability and quality of products. These are presented first using a single-trait approach and subsequently using multitrait approaches, the latter allowing the detection of plQTL. Finally, multitrait detections are presented for plQTL related to more than 1 of our 3 groups of traits. Significant QTL exceeding the 1\% chromosome-wide threshold (in single-trait and multitrait detections) are detailed in Tables 2 to 8; suggestive QTL under the 1\% chromosome-wide threshold (in single-trait detections) are presented in Appendices 5, 6, and 7.
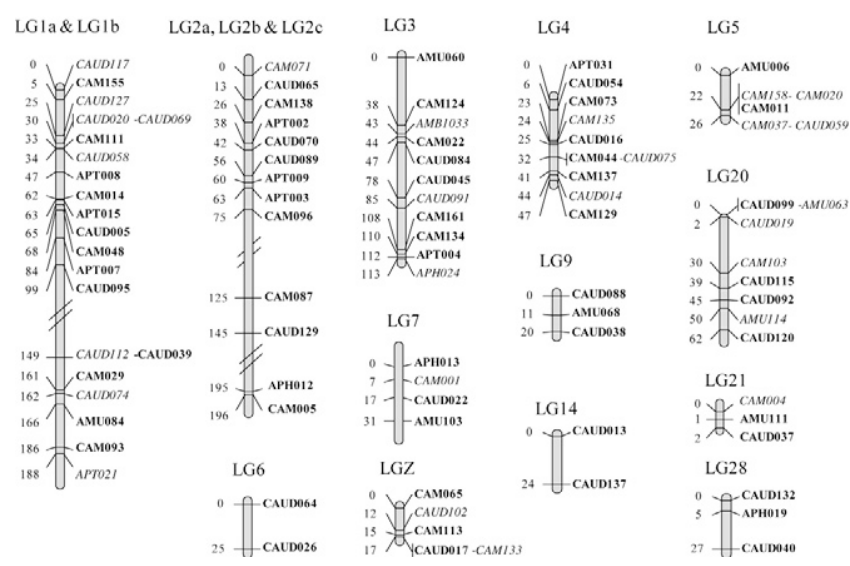

Figure 2. Sex-averaged genetic map in centiMorgans. Linkage groups (LG) were built using the Crimap software: markers in boldface belong to the framework map, and markers in italics belong to the putative map.

\section{Traits Related to Growth}

Quantitative trait loci for growth traits are presented in Table 2 for the single-trait approach, and in Table 3 for the multitrait plQTL approach.

Single-trait analysis. Two QTL for BW28 (BW on d 28) and BWG12-28 (BW gain from d 12 to d 28), both highly significant at the chromosome-wide level ( $P$-value $=0.0023$ and 0.0028 , respectively), were detected by the single-trait analyses on LG 3. Seven other suggestive QTL ( $P$-value $>0.05$, Appendix 5) for BW42, BW70, BWG12-28, BWG12-42, BWG12-70, BWG28-42, and BWG28-70, were co-localized on LG2a. The Weibull curve approach led to the detection of 3 new QTL: 2 QTL for Ti on LG7 $(P$-value $=0.0064)$ and LG1a, respectively (Appendix 5), and 1 QTL for $\mathrm{BW}_{\mathrm{A}}$ on LG20 (Appendix 5). The QTL for Ti on LG7 presented a relatively strong QTL effect of 0.30 in phenotypic deviation units. The lack of highly significant QTL for $\mathrm{BW}_{\mathrm{A}}$ is consistent with the absence of QTL for the BW at $70 \mathrm{~d}$, because both traits are highly correlated $(r=0.78)$.

Multiple-Trait Analysis. Neither the co-localized QTL approach nor the correlation between traits approach resulted in the confirmation of existing QTL or the identification of new QTL. The multitrait detection for BW28 and BWG12-28, which are strongly correlated $(r=0.92)$ and presented 2 co-localized QTL on LG3, did not reveal any plQTL reaching the $1 \%$ threshold on LG3. However, by combining the 2 Weibull parameters ( $\mathrm{Ti}$ and $\mathrm{BW}_{\mathrm{A}}$ ), multitrait analysis identified a new plQTL, significant at the $1 \%$ threshold, on LG21 (Table 3). This is consistent with the observation that, in single-trait analysis, the likelihood ratio tests (LRT) on LG21 were nearly significant for both $\mathrm{Ti}$ and $\mathrm{BW}_{\mathrm{A}}$.

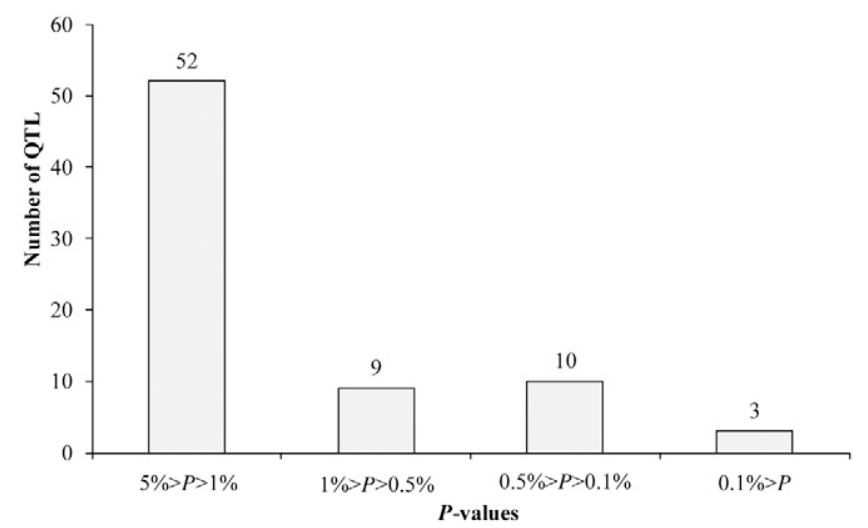

Figure 3. The QTL frequencies by chromosome-wide significance levels (4 classes of $P$-values). 
Table 2. Growth traits - single-trait analysis

\begin{tabular}{|c|c|c|c|c|c|c|c|c|}
\hline $\mathrm{LG}^{1}$ & Traits $^{2}$ & Flanking markers $^{3}$ & Location $^{4}$ & $\mathrm{LRT}_{x}^{5}$ & $P$-value & Threshold $^{6}$ & Mean within family substitution effect ${ }^{7}$ & Confidence interval \\
\hline 3 & BW28 & CAM022-CAUD084 & 46 & 29.10 & 0.0023 & $00 / \dagger$ & 0.14 & 33 to 64 \\
\hline 3 & BWG12-28 & CAUD084-CAUD045 & 51 & 27.75 & 0.0028 & $0 / \uparrow$ & 0.19 & 35 to 65 \\
\hline 7 & $\mathrm{Ti}$ & APH013 & 0 & 21.93 & 0.0064 & 0 & 0.30 & 0 to 6 \\
\hline
\end{tabular}

${ }^{1} \mathrm{LG}=$ linkage group.

${ }^{2} \mathrm{BW} 28=\mathrm{BW}$ at $28 \mathrm{~d}$ of age; BWG12-28 = BW gain between 12 and $28 \mathrm{~d}$ of age; $\mathrm{T}_{\mathrm{i}}=$ age at inflection point.

${ }^{3}$ Flanking markers of the most probable QTL position.

${ }^{4}$ Most probable QTL position, in cM.

${ }^{5} \mathrm{LRT}_{x}=$ maximum likelihood ratio for $x$ locus.

${ }^{6}$ Level of significance of $P$-value. Chromosome-wide: $\bullet=0.01>P>0.005 ; \bullet=0.005>P>0.001$. Genome-wide: $\dagger=0.05>P>0.01$.

${ }^{7}$ QTL effect in phenotypic deviation units (SD), and estimated as $\alpha=\frac{1}{\mathrm{SD}} \times \frac{1}{n} \sum_{i=1}^{n}\left|\alpha_{i}\right|$.

\section{Traits Related to BW and Metabolism During the Overfeeding Period}

The QTL related to metabolism traits during overfeeding $(P$-value $<0.01)$ are presented in Tables 4 and 5 for single and multitrait analyses, respectively.

Single-Trait Analysis. Only 1 strong QTL ( $P$-value $=$ 0.0020 ) was found for plasma triglyceride content after the 20th overfeeding meal on LGZ (corresponding to the $\mathrm{Z}$ gonosome) with a large QTL substitution effect. No significant QTL, and only 1 suggestive QTL (Appendix 6), were identified for any of the other traits related to blood plasma contents or to the stage of the overfeeding process. For the 2 traits related to the ease of handling the animals during overfeeding, 2 QTL were detected $(P$-value $<0.01): 1$ was highly significant QTL $(P$-value $=$ 0.0002 ) and mapped to LG4. Finally, 15 suggestive QTL $(P$-value $<0.05$; Appendix 6$)$ were scattered over 9 different LG: 4 LG contained co-localized QTL and 5 had isolated QTL. Briefly, the plasma cholesterol content was affected by QTL on LG2c, 3, 14, and 21, whereas the plasma triglyceride content was influenced by QTL on 2 of these 4 LG (LG14 and LG21). The main QTL involved in the genetic determinism of glucose content were located on 3 other LG (LG2a, 6 and 28). Finally, LG7 and LG28 carried QTL affecting BW at the beginning of the overfeeding period, whereas 2 QTL on LG9 and LG21 affected the BW gain during the overfeeding period and the BW at the end of overfeeding period, respectively.

Multiple-Trait Analysis. The co-location criteria on LG2a, LG14, and LG21, and the correlation criteria between the cholesterol and triglyceride contents after the 10 th meal revealed 4 potential plQTL areas, 2 of which were located on LG14. A strong plQTL $(P$-value $<0.001)$ was mapped to LG2a by combining the corticosterone concentration before stress and the glucose content at the second meal. Another strong plQTL $(P$-value $<0.001)$ was confirmed on LG21 for cholesterol and triglyceride contents at the 10th overfeeding meal. This plQTL was detected both by the analysis of 2 co-located singletrait QTL on LG21 and by the analysis of correlated traits. The correlated-trait approach for triglyceride and cholesterol contents after the 10th meal also revealed a new, weaker plQTL on LG14 $(P$-value $<0.01)$. This result is consistent with the plQTL $(P$-value $<0.005)$ mapped to LG14 after the analysis based QTL colocalization of the cholesterol content after the 10th meal and the triglyceride content after the second meal. For this last plQTL, the correlated-trait approach also reduced the confidence interval to 0 to $17 \mathrm{cM}$, whereas it was, respectively, 0 to $22 \mathrm{cM}$ and 0 to $24 \mathrm{cM}$ for TG2nd and $\mathrm{CHO} 10$ th in single-trait detections. Thus, 2 plQTL were found on LG14 for the triglyceride content after the second or the 10th meal, combined with the cholesterol

Table 3. Growth traits - multitrait analysis

\begin{tabular}{|c|c|c|c|c|c|c|c|c|}
\hline $\mathrm{LG}^{1}$ & Trait group and type ${ }^{2}$ & Traits $^{3}$ & Flanking markers ${ }^{4}$ & Location $^{5}$ & $\mathrm{LRT}_{x}{ }^{6}$ & Threshold $^{7}$ & Mean within family substitution effect ${ }^{8}$ & Confidence interval \\
\hline \multirow[t]{2}{*}{21} & $\mathrm{PC}$ & $\mathrm{BW}_{\mathrm{A}}$ & CAM004 & 0 & 25.96 & $\bullet$ & 0.12 & 0 to 2 \\
\hline & & $\mathrm{T}_{\mathrm{i}}$ & & & & & 0.11 & \\
\hline \multicolumn{9}{|c|}{${ }^{1} \mathrm{LG}=$ linkage group. } \\
\hline \multicolumn{9}{|c|}{${ }^{2}$ Criteria to select the traits for multitrait analysis: $\mathrm{PC}=$ phenotypic correlation. } \\
\hline \multicolumn{9}{|c|}{${ }^{3} \mathrm{BW}_{\mathrm{A}}=$ Asymptotic $\mathrm{BW} ; \mathrm{T}_{\mathrm{i}}=$ age at inflection point. } \\
\hline \multicolumn{9}{|c|}{${ }^{4}$ Flanking markers of the most probable QTL position. } \\
\hline \multicolumn{9}{|c|}{${ }^{5}$ Most probable QTL position, in cM. } \\
\hline \multicolumn{9}{|c|}{${ }^{6} \mathrm{LRT}_{x}=$ maximum likelihood ratio for $x$ locus. } \\
\hline \multicolumn{9}{|c|}{${ }^{7}$ Level of significance of $P$-value. Chromosome-wide: $\mathbf{0}=0.01>P>0.005$. } \\
\hline \multicolumn{9}{|c|}{${ }^{8} \mathrm{QTL}$ effect in phenotypic deviation units (SD), and estimated as $\alpha=\frac{1}{\mathrm{SD}} \times \frac{1}{n} \sum_{i=1}^{n}\left|\alpha_{i}\right|$. } \\
\hline
\end{tabular}


Table 4. Metabolic and BW traits during the overfeeding phase - single-trait analysis

\begin{tabular}{|c|c|c|c|c|c|c|c|c|}
\hline$\overline{\mathrm{LG}^{1}}$ & Traits $^{2}$ & Flanking markers ${ }^{3}$ & Location $^{4}$ & $\mathrm{LRT}_{x}^{5}$ & $P$-value & Threshold $^{6}$ & Mean within family substitution effect ${ }^{7}$ & Confidence interval \\
\hline $2 \mathrm{a}$ & FO 20thM & CAM138-APT002 & 28 & 24.67 & 0.0084 & $\bullet$ & 0.34 & 15 to 37 \\
\hline 4 & FC 2ndM & CAM137 & 41 & 34.71 & 0.0002 & $000 / \dagger+$ & 0.23 & 38 to 44 \\
\hline Z & TG 20thM & CAM065-CAUD102 & 1 & 26.54 & 0.0020 & $\bullet$ & 0.48 & 0 to 8 \\
\hline \multicolumn{9}{|c|}{${ }^{2} \mathrm{FC} 2 \mathrm{ndM}=$ catching ease at second meal; $\mathrm{FO} 20 \mathrm{thM}=$ overfeeding ease at 20th meal; TG 20thM = plasma triglyceride content at 20th meal. } \\
\hline \multicolumn{9}{|c|}{${ }^{3}$ Flanking markers of the most probable QTL position. } \\
\hline \multicolumn{9}{|c|}{ 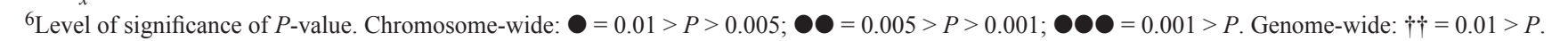 } \\
\hline
\end{tabular}

content after the 10th meal. Indeed, both single-trait QTL for TG2nd and CHO10th were suggestive ( $P$-values of approx. 0.03), whereas the $P$-value for TG10th reached only 0.06 . The close location of the 2 plQTL suggests that they may be due to 1 plQTL affecting the 3 traits.

\section{Traits Related to Overfeeding Ability and Quality of Products}

The QTL related to the overfeeding ability and product quality traits are presented in Tables 6 and 7 for the single and multitrait analyses, respectively.

Single-Trait Analysis. In single-trait detection, 16 significant QTL $(P$-value $<0.01)$ were identified in 7 different LG, with QTL related to muscle quality traits clustering on LG2a, and LG2c and LG9 harboring in particular QTL for fatty liver quality traits. The 2 strongest QTL $(P$-value $=0.0004$, reaching the $1 \%$ genome-wide threshold) were identified on LG4 for muscle $\mathrm{pH} 20$ min post mortem and on LG2a for muscle cooking losses (Fig. 4). The LG2a also harbored 2 QTL for lipid muscle content and muscle maximal shear force $(P$-value $=0.0028$ and $P$-value $=0.0053$, respectively $)$. Finally, in regard to breast meat quality, a QTL for the variation of muscle cooking losses was mapped to LG6 $(P$-value $=0.0018)$. The variability of fatty liver weight was partly controlled by 3 QTL on LG21, LG9, and LG2c. Moreover, the latter 2 LG (LG9 and LG2c) also have QTL related to fatty liver quality. On LG2c, 2 QTL for lipid and protein contents $(P$-value $=0.0060$ and $P$-value $=0.0046$, respectively) were co-localized with the fatty liver weight QTL $(P$-value $=0.0084)$ and interestingly, these 3 traits are highly correlated. On LG9, 2 QTL for protein content and liver redness were detected $(P$-value $=0.0062$ and $P$-value $=0.0024$, respectively $)$, but only the QTL for liver protein content (LprotC) and fatty liver weight co-localized. On LG21, 3 QTL were detected for carcass weight, fatty liver texture, and fatty liver weight $(P$-value $=0.0030, P$-value $=0.0024$, and $P$-value $=0.0026$, respectively $)$.

Table 5. Metabolic and BW traits during the overfeeding phase-multitrait analysis

\begin{tabular}{|c|c|c|c|c|c|c|c|c|}
\hline$\overline{\mathrm{LG}^{1}}$ & Trait group and type ${ }^{2}$ & Traits $^{3}$ & Flanking markers ${ }^{4}$ & Location $^{5}$ & $\mathrm{LRT}_{x}^{6}$ & Threshold $^{7}$ & Mean within family substitution effect ${ }^{8}$ & Confidence interval \\
\hline \multirow[t]{2}{*}{$\overline{2 a}$} & CQ (2a) & GLU2ndM & CAM071-CAUD065 & 12 & 40.55 & $000 / \uparrow$ & 0.11 & 0 to 18 \\
\hline & & CortL & & & & & 0.15 & \\
\hline 14 & & TG 2ndM & & & & & 0.15 & \\
\hline \multirow[t]{2}{*}{14} & $\mathrm{PC}$ & CHO10thM & CAUD013-CAUD137 & 20 & 27.33 & $\bullet$ & 0.11 & 6 to 24 \\
\hline & & TG 10thM & & & & & 0.08 & \\
\hline 21 & PC & TG 10thM & & & & & 0.10 & \\
\hline
\end{tabular}

\footnotetext{
${ }^{1} \mathrm{LG}=$ linkage group.

${ }^{2}$ Criteria to select the traits for multitrait analysis: $\mathrm{CQ}=$ co-located $\mathrm{QTL}$ and $\mathrm{PC}=$ phenotypic correlation.

${ }^{3} \mathrm{CortL}=$ corticosterone concentration before stress; $\mathrm{CHO} 10 \mathrm{thM}=$ plasma cholesterol content at 10th meal; GLU 2ndM = plasma glucose content at second meal; TG 2ndM = plasma triglyceride content at second meal; TG 10thM = plasma triglyceride content at 10th meal.

${ }^{4}$ Flanking markers of the most probable QTL position.

${ }^{5}$ Most probable QTL position, in cM.

${ }^{6} \mathrm{LRT}_{x}=$ maximum likelihood ratio for $x$ locus.

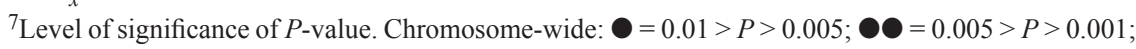

${ }^{8} \mathrm{QTL}$ effect in phenotypic deviation units (SD), and estimated as $\alpha=\frac{1}{\mathrm{SD}} \times \frac{1}{n} \sum_{i=1}^{n}\left|\alpha_{i}\right|$.
} 
Multiple-Trait Analysis. Multitrait analyses (Table 7) revealed 9 plQTL, 8 of which related to product quality and mainly to liver quality. Four plQTL on LG2c, LG3, and LG9 with very significant thresholds $(P$-value $<0.05)$ were suggested by the co-localization of single-trait QTL, whereas the 5 other plQTL were new, identified by the joint analysis of 3 pairs of traits. These multitrait analyses confirmed the importance of LG2c in the variability of the liver melting rate, when this trait is associated with the structural composition of the liver (such as protein content or collagen content) and, to a lesser extent, that of LG9 for the variability of liver composition. LG3 seemed to harbor 3 plQTL: 1 for liver yellowness and spots on the liver due to viscera at the beginning of the LG, for which the confidence interval ( 0 to $16 \mathrm{cM}$ ) was reduced as compared with singletrait detections ( 0 to $19 \mathrm{cM}$ for $\mathrm{Lb}^{*}$ and 0 to $26 \mathrm{cM}$ for ESV); and 2 others toward the center (at $85 \mathrm{cM}$, when combining melting rate and liver protein content) and the end (at $108 \mathrm{cM}$, when combining liver protein and lipid content) of the LG. One strong plQTL for liver composition traits was detected $(P$-value $<0.001)$ on LG7; this was a new and unexpected finding because no QTL were detected $(P$-value $>0.05)$ for any of the traits forming this group with the single-trait approach. Lastly, the combination of 2 muscle rheological traits (energy needed to cut the breast muscle and maximal shear force) led to the identification of a plQTL on LG5.

\section{Pleiotropic QTL Influencing Phenotypes Across Groups of Traits}

The most significant multitrait plQTL detected that act simultaneously on 2 or more traits belonging to different groups of traits (growth, BW and metabolism during overfeeding, and overfeeding ability and quality of products) are presented in Table 8. Because these traits can refer to very different physiological functions, correlations between the traits were usually low (all under 0.55) so multitrait QTL detection across groups of traits was only performed for those with co-localized QTL.

Four plQTL were detected on LG7, LG9, and LG21, among which 3 reached the $0.1 \%$ threshold. Association of weight gain during the overfeeding period and fatty liver weight traits on LG9 led to the detection of a strong plQTL ( $P$-value $<0.001,5 \%$ genome-wide threshold) with a smaller QTL confidence interval, reduced from positions 5 to $20 \mathrm{cM}$ and 8 to $20 \mathrm{cM}$ for FLW and overfeeding period (OWG), respectively, down to position 11 to $20 \mathrm{cM}$ for the plQTL. On LG21, a plQTL was detected by combining carcass weight and BW at the end of overfeeding period $(P$-value $<0.001)$. This

Table 6. Overfeeding ability and product quality traits — single-trait analysis

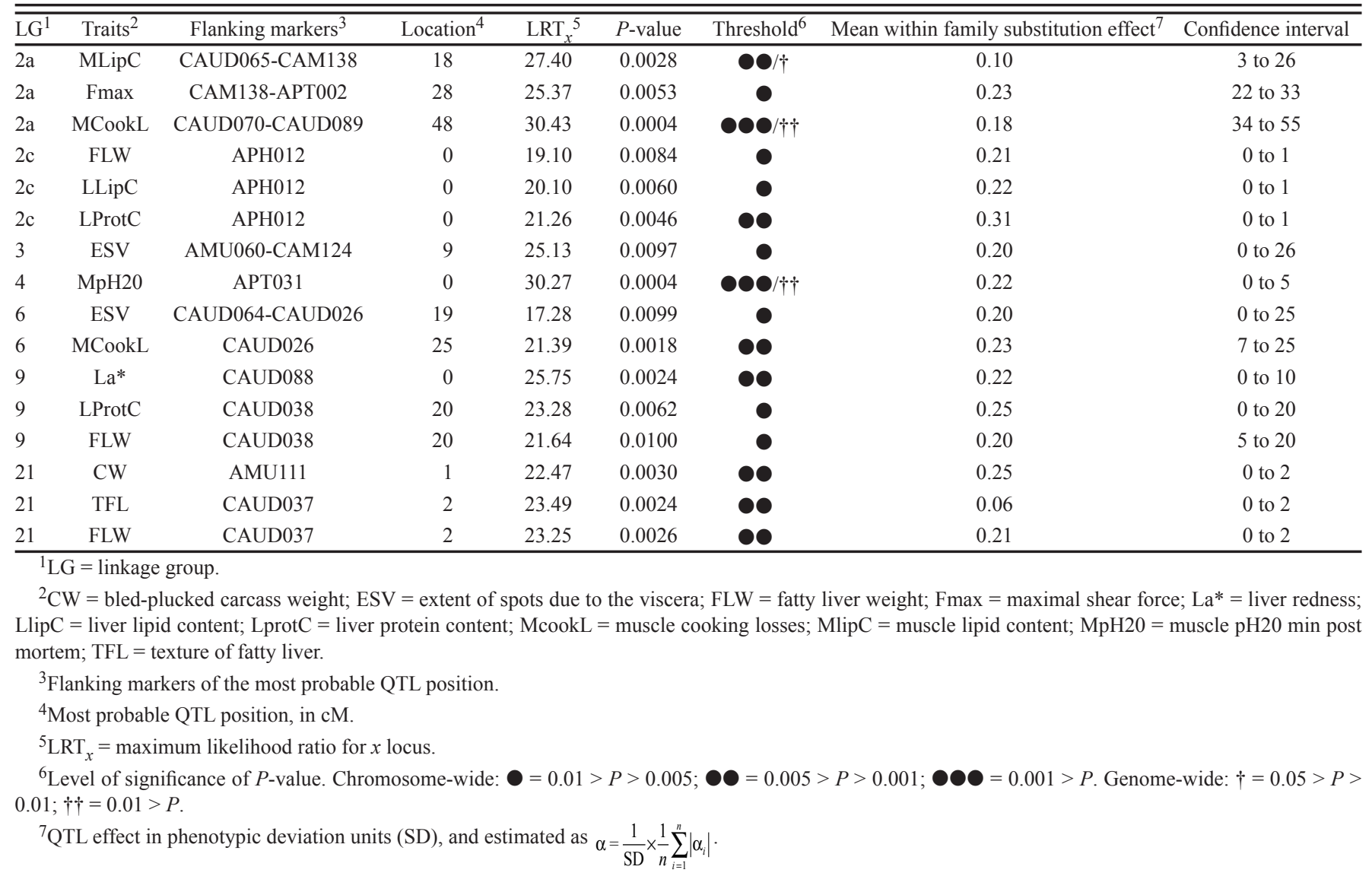


plQTL is probably mostly due to $\mathrm{CW}$, for which a QTL was also detected on LG21 by single-trait analysis. Another plQTL was observed on LG21 by associating ease of overfeeding measured at the 10th meal and liver collagen content $(P$-value $<0.001)$. This plQTL was characterized by a sharp increase in the power of detection because the single-trait detection threshold was only $5 \%$ for both traits. Finally, the combination of BW at the beginning of overfeeding period and BW gain between $\mathrm{d} 42$ and 70 resulted in the detection of a plQTL on LG7 although this LG had not been identified previously as impacting late growth.

In summary, the positions of the 22 single-trait QTL and the 18 multiple-trait QTL are represented in Fig. 5.

\section{DISCUSSION}

This paper reports the first study aimed at detecting QTL in overfed waterfowl in which trait measurements were obtained by progeny testing on sterile interspecific hybrid ducks. As a first step of our exploration, singletrait analysis resulted in the detection of 22 QTL significant at the $1 \%$ chromosome-wide threshold (to which should be added 52 suggestive QTL). The ratios between the number of QTL detected and the number of traits recorded for a given physiological function are very variable: very few QTL were detected for traits related to metabolism (such as blood lipid metabolism traits during overfeeding and corticosterone concentrations during growth) or growth, whereas, in proportion, many more QTL were detected for traits related to liver and muscle quality. Subsequently, 18 plQTL were identified by multitrait analysis, with at least 7 of them mapping to new chromosomal regions not identified previously by univariate analysis. Indeed, multitrait QTL analysis was performed either i) on groups consisting of correlated traits, or ii) on traits QTL located close to one another after detection by single-trait analysis. In the latter case (ii), the estimated positions of the plQTL were similar to 1 of the positions found by single-trait QTL analysis, and moreover, the confidence interval was generally reduced. This is consistent with Gilbert and Le Roy (2003), who demonstrated that the use of information from distinct correlated traits sharing a plQTL increases the precision of the estimated location of this QTL. This approach highlighted the most interesting chromosomal regions, especially for traits related to fatty liver and breast muscle quality. The other grouping method (correlation

Table 7. Overfeeding ability and product quality traits - multitrait analysis

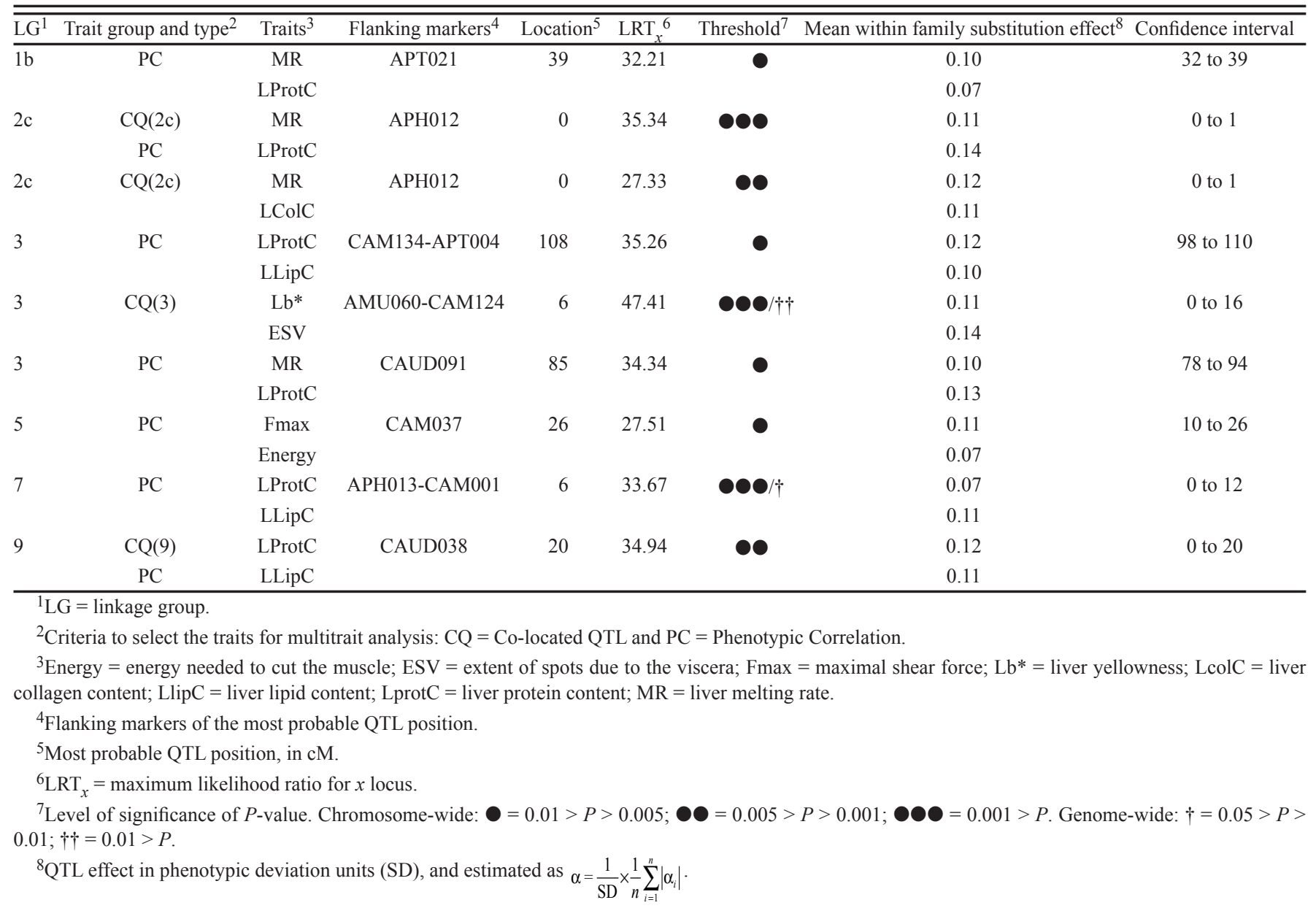




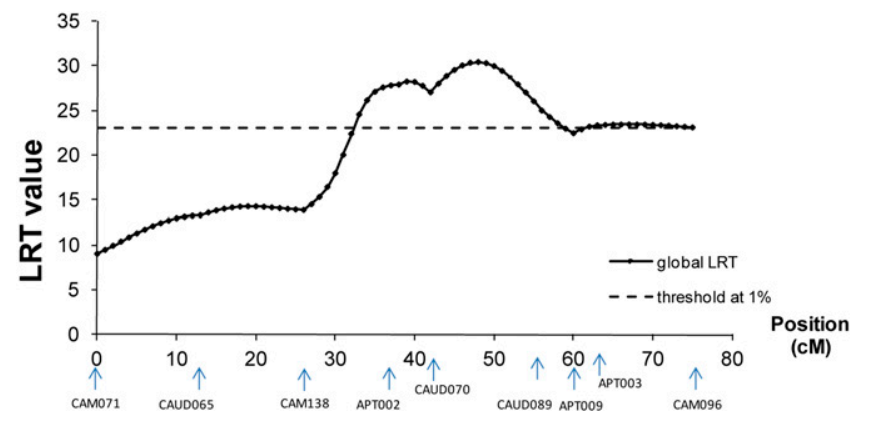

Figure 4. Global likelihood ratio test (LRT) profile for the muscle cooking losses trait on the Linkage Group 2a, with a threshold at $1 \%$ at the chromosome-wide level. The positions of markers (in centiMorgans) on Linkage Group 2a are shown on the $x$ axis.

criteria) led to the identification of several new QTL. These QTL could not be detected by single-trait analysis because of their small effects: the information gain obtained with the combination of these correlated traits was particularly interesting for duck metabolism traits.

The statistical analyses were performed with some approximations, and the data were precorrected for significant nuisance effects evidenced by SASGLM. This 2-step procedure greatly simplified the calculations, in particular for multitrait analysis, and is generally considered as safe in terms of the estimation of QTL location (McRae et al., 2005; Lillehammer et al., 2009). As demonstrated by Crooks et al. (2009) for the polygenic effect, when data are precorrected, possible confusion between certain levels of a nuisance effect and transmitted QTL alleles could result in underestimation of the QTL effect and loss of power. It must be emphasized that this approach is conservative and should not result in false QTL detection. Because the traits analyzed were the means of the performances of the offspring (mule ducks) of BC dams, the variability of their variances had to be considered in the model. Both heritabilities and genetic to phenotypic covariance ratios were given as parameters and not estimated with QTL effects. This is clearly an approximation which supposes that the QTL effects are not too strong. This 2-step procedure is in the line of the GRAMMAR model for association analysis developed by Aulchenko et al. (2007). The backward approach used for multitrait detection generated a great number of statistical tests, and the significance of the results must often be considered with caution. However, the improvement of QTL localization generated by this approach is probably free of this drawback.

Regarding the duck genetic map, previous reports have shown the strong conservation of synteny between ducks and chickens (Fillon et al., 2007; Skinner et al., 2009) and has led to a proposed nomenclature for duck chromosomes based on that of chickens (Skinner et al., 2009). In these studies, the major rearrangement observed between the duck and chicken karyotypes involves the ancestral chromosomes 4 and 10, which have fused in the chicken lineage to give GGA4, but remain separate in ducks. Apart from this single interchromosomal rearrangement, it was demonstrated that synteny was conserved between the 2 species, including all microchromosomes analyzed. We thus consider here that duck chromosomes APL1 to APL9 correspond to chicken chromosomes GGA1 to GGA9, that APL10 corresponds to GGA4p and finally, that the rest of the karyotype is offset by 1 , with GGA10 corresponding to APL11, and so on. Therefore, the number of the LG used in our genetic map was the number of the corresponding duck chromosomes (APL). As some of our independent LG were located by BLAST search on the same chicken

Table 8. Mixed group - multitrait analysis

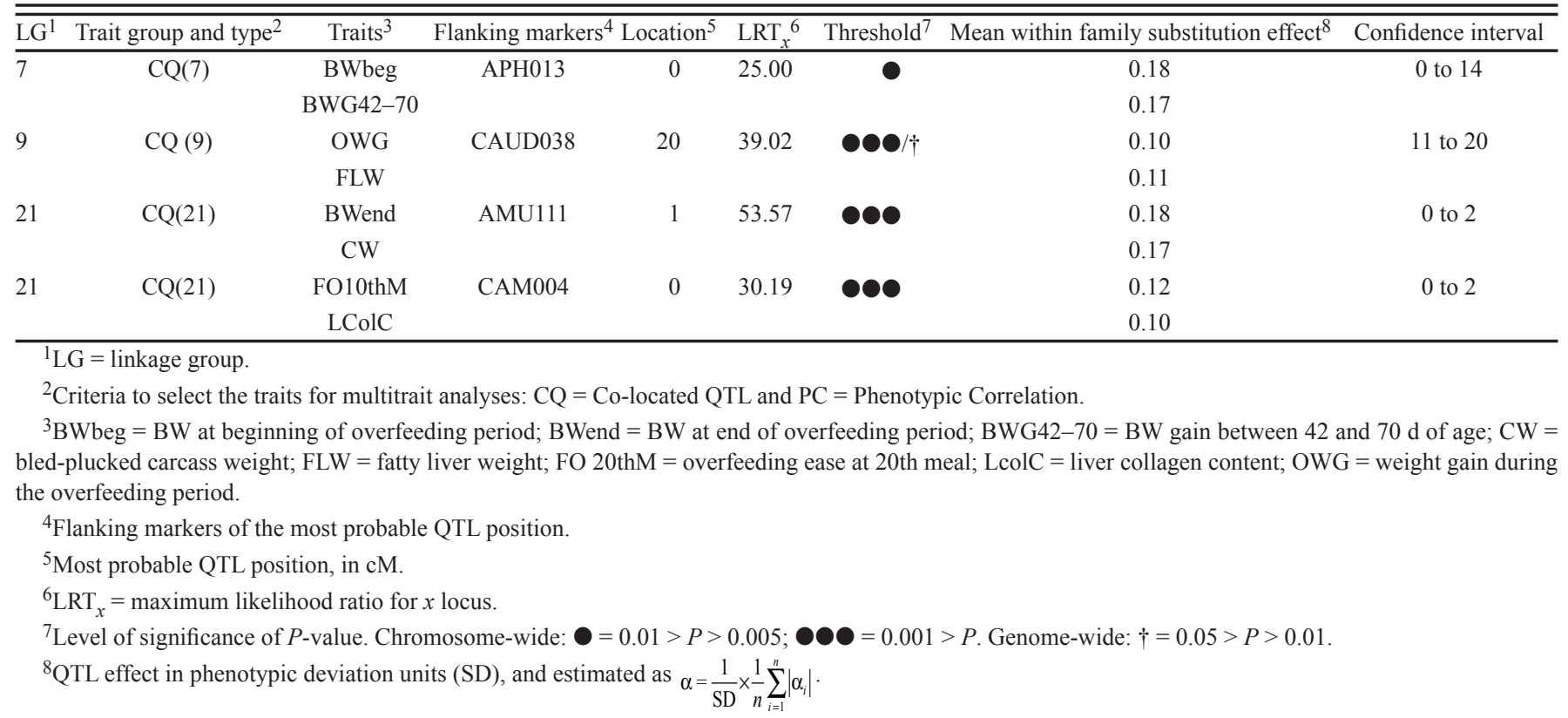


chromosome, we used letters in the nomenclature to distinguish between them (e.g., LG1a and LG1b for 2 independent LG assigned to GGA1).

Twelve of the 22 significant QTL concerned original traits such as liver quality (7 QTL) and muscle quality (5 QTL) in overfed ducks. Some of these traits, especially the latter, correspond to traits studied in chickens. The karyotypes of the 2 species are very similar, with only 1 interchromosomal rearrangement detected to date (Fillon et al., 2007; Skinner et al., 2009), suggesting that QTL located on orthologous chromosomes could be equivalent. However, further investigations must be performed to refine duck QTL location and chickenduck intrachromosomal rearrangements. Most of the strongest QTL for traits related to breast muscle quality (concerning cooking losses, lipid content, and maximal shear force to cut the muscle) were gathered on LG 2a: the QTL for MCookL and for muscle lipid content (MLipC) reached the 1 and 5\% genome-wide thresholds, respectively. In Beijing-You chickens, Ye et al. (2010) assessed the association of SNP in the fatty acid binding proteins $(\boldsymbol{A}-\boldsymbol{F A B P})$ gene, located on GGA2, with the content of intramuscular fat (IMF). Another QTL for muscle cooking losses was detected on LG6, and this is consistent with Huang et al. (2007a) who described a QTL for the MCookL trait on CAU6, although the breast muscle was not fattened by overfeeding. Regarding $\mathrm{pH} 20$ min post mortem, a strong QTL reaching the $1 \%$ genome-wide threshold was detected on LG4. In chickens, a QTL for breast meat ultimate $\mathrm{pH}$ was mapped using QTL Express software by Wright et al. (2006) and Nadaf et al. (2007) to chromosome 4 at $233 \mathrm{cM}$ and $201 \mathrm{cM}$, respectively. Although the trait involved in the 2 poultry species is not exactly the same (ultimate $\mathrm{pH}$ in chickens versus $\mathrm{pH} 20 \mathrm{~min}$ post mortem in ducks), it is quite surprising that the QTL of both species are located on LG4 as the chicken is a white meat type species and the duck is a red meat type. Finally, a plQTL for meat texture (energy needed to cut the muscle and maximal shear force traits) was identified by multitrait analysis on
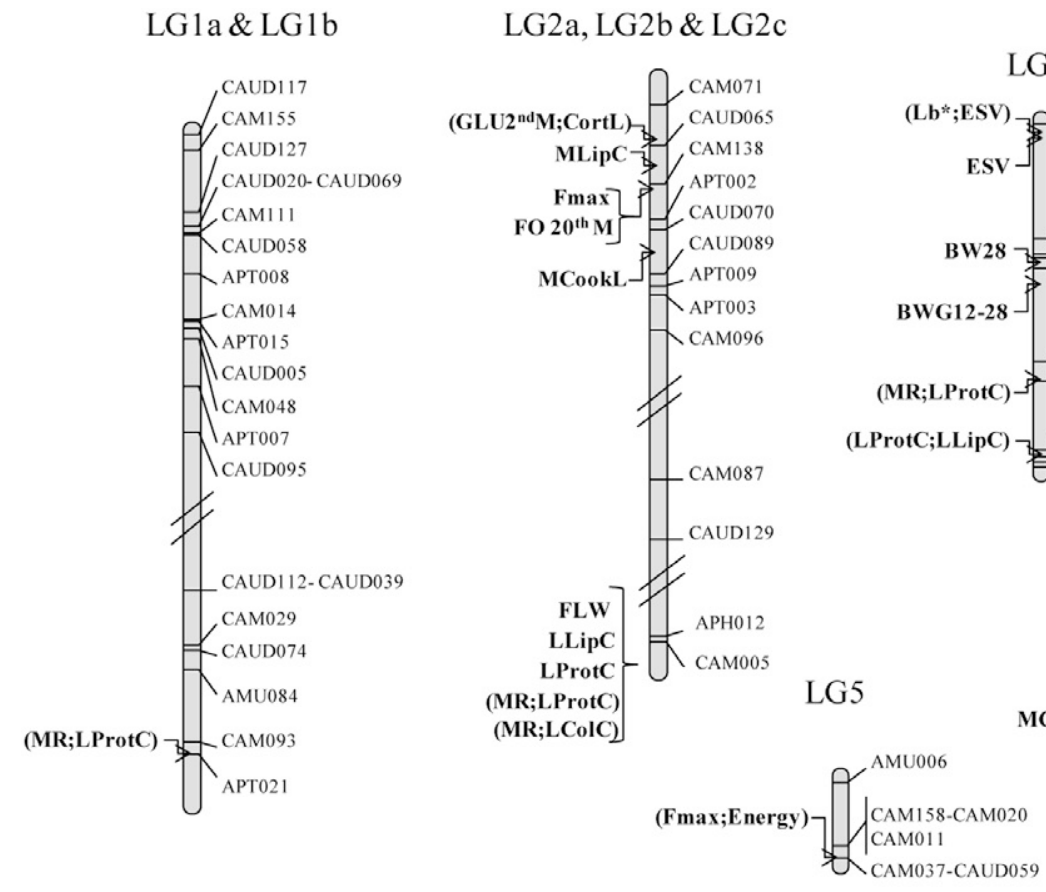

LG14

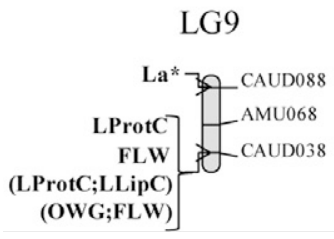

LG5

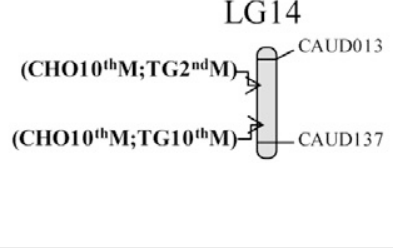

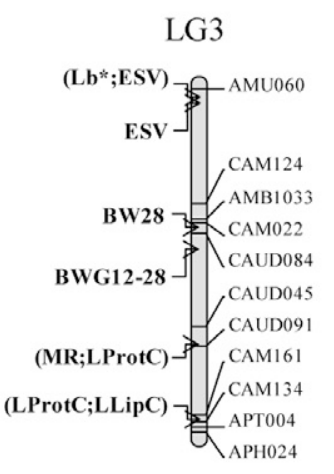

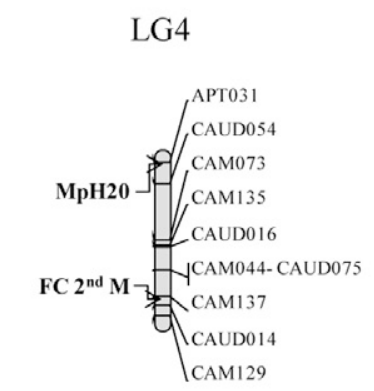

\section{LG7}

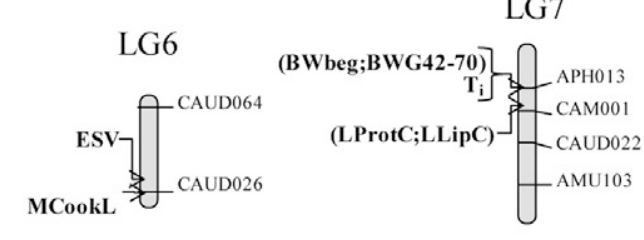

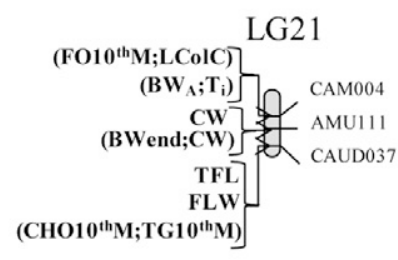

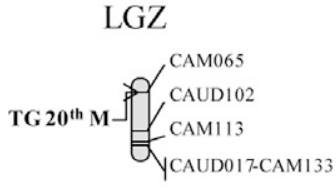

Figure 5. Position of the single-trait and multitrait QTL on the sex-averaged genetic map. Only linkage groups on which QTL were detected are represented below. Multitrait $\mathrm{QTL}$ are in parentheses. $\mathrm{BW}_{\mathrm{A}}=$ asymptotic $\mathrm{BW}$; $\mathrm{BWbeg}=\mathrm{BW}$ at beginning of overfeeding period; $\mathrm{BWend}=\mathrm{BW}$ at end of overfeeding period; $\mathrm{BW} 28=\mathrm{BW}$ at $28 \mathrm{~d}$ of age; BWG12-28 $=\mathrm{BW}$ gain between 12 and $28 \mathrm{~d}$ of age; BWG42-70 = BW gain between 42 and $70 \mathrm{~d}$ of age; CortL = corticosterone concentration before stress; $\mathrm{CHO} 10$ thM $=$ plasma cholesterol content at 10th meal; $\mathrm{CW}=$ bled-plucked carcass weight; Energy = energy needed to cut the muscle; ESV = extent of spots due to the viscera; FC 2ndM = catching ease at second meal; FLW = fatty liver weight; Fmax = maximal shear force; FO 20thM $=$ overfeeding ease at 20th meal; GLU 2ndM = plasma glucose content at second meal; La* $=$ liver redness; Lb* $=$ liver yellowness; LColC $=$ liver collagen content; LLipC = liver lipid content; LProtC = liver protein content; $\mathrm{MCookL}=$ muscle cooking losses; $\mathrm{MLipC}=$ muscle lipid content; $\mathrm{MpH} 20=$ muscle $\mathrm{pH} 20$ min post mortem; $M_{\mathrm{R}}=$ liver melting rate; $\mathrm{OWG}=$ weight gain during the overfeeding period; TFL = texture of fatty liver; TG $2 \mathrm{ndM}=$ plasma triglyceride content at second meal; TG 10thM = plasma triglyceride content at 10th meal; TG 20thM = plasma triglyceride content at 20th meal; $\mathrm{T}_{\mathrm{i}}=$ age at inflection point. 
LG5; but, to our knowledge, there are no published data on this type of trait in chickens.

More specifically, QTL related to fatty liver quality cannot be compared with any previously published results, because the present work is the first design for QTL detection in overfed waterfowl. In chromosomal regions 2c, 7, and 9, remarkable clusters of QTL simultaneously impacting at least 2 of these 4 traits (liver melting rate, lipid, protein or collagen contents) were observed. These trait associations are very consistent, as collagen and proteins are considered important for structuring the fatty liver tissue: a variation of the liver extracellular matrix would logically impact on its capacity to store lipids and on the liver melting rate. Indeed, recent work has highlighted the role of the protein fraction in the biological determinism of the technological quality of fatty livers (Théron et al., 2011). On LG2c, the strongest improvement of the power of QTL detection was obtained by associating the melting rate and liver protein content, whereas the plQTL on LG7 and LG9 were more related to liver composition (lipid and protein content).

Regarding the overfeeding ability traits, 2 of the 3 QTL influencing fatty liver weight were mapped to LG2c and LG9, and co-localized with QTL for liver quality traits. However, greater $P$-values were obtained for plQTL when 2 co-localized liver quality traits were associated than when liver weight and a liver quality trait were associated. The co-localization of QTL for traits measured independently consolidates the reliability of our results, but the chromosomal regions that we identified did not match previously published results in other birds. Indeed, in ducks or chickens, most of the previously detected liver weight QTL did not intersect our QTL locations: 3 significant areas on LG4, LG6, and CAU7 (corresponding to our LG20) were reported in lean Pekin ducks (Huang et al., 2007a), and 3 others were reported on GGA1, GGA8, and GGA12 (corresponding to our LG13) in chickens (Wright et al., 2006). Only Gao et al. (2009) reported a liver weight QTL on the GGA2, which had a confidence interval covering onehalf of the chromosome in a F2 cross between Silkie fowl and White Plymouth Rock chickens.

Regarding growth traits, only 3 QTL were detected: 2 for growth between 12 and $28 \mathrm{~d}$ of age on LG3 (at the $5 \%$ genome-wide threshold) and 1 on LG7 (at the $1 \%$ chromosome-wide threshold). These results are consistent with those found in chickens where GGA3 is an interesting chromosome for growth traits with more than 50 QTL identified (www.animalgenome.org, $\mathrm{Hu}$ et al., 2010) and numerous publications highlighting QTL related to the development of young birds (Siwek et al., 2004; Atzmon et al., 2008; Ambo et al., 2009; Wahlberg et al., 2009). Maruyama et al. (2001) and Vitezica et al.
(2010) demonstrated that the Weibull function is the best model for fitting duck BW data, compared with other models such as Gompertz, logistic, von Bertalanffy, Morgan-Mercer-Flodin, or Spline. Performing QTL detections using Weibull parameters has highlighted a new area of interest for growth traits on LG7, which has a plQTL for growth between 42 and $70 \mathrm{~d}$ of age and BW at the beginning of the overfeeding period. Moreover, GGA7 is also known to contain 28 growth trait QTL in chickens (Zhou et al., 2007; Atzmon et al., 2008; Ambo et al., 2009). Nevertheless, the Pekin duck experimental design analyzed by Huang et al. (2007b) revealed 4 chromosomal areas (2 QTL on LG1 and 2 other QTL on LG2 at the 5\% genome-wide threshold) impacting growth traits which were different from our QTL locations.

The use of the multitrait approach within growth traits only resulted in the detection of 1 new QTL when gathering both Weibull parameters $\left(\mathrm{Ti}\right.$ and $\left.\mathrm{BW}_{\mathrm{A}}\right)$ on LG21. By comparing this result with the QTL detected for the BW at the end of overfeeding and the carcass weight on LG21, we could hypothesize that this QTL area modifies both the growth curve and the final product (i.e., carcass weight). In a specific intercross between 2 chicken lines divergently selected for juvenile BW, Wahlberg et al. (2009) identified 7 regions harboring QTL influencing growth (GGA1, GGA3, GGA4, GGA7, and GGA20) including a network of interacting loci on GGA7. Knowing that GGA20 corresponds to APL21 and the short arm of GGA4 to APL10 (Skinner et al., 2009), for which we have no marker yet, we could highlight the consistency between our LG containing QTL for growth traits in young birds, and the results described by Wahlberg et al. (2009) in chickens.

Regarding metabolism traits, we only detected 1 QTL for triglyceride content in blood at the end of the overfeeding period. This QTL, located on LGZ (at the 1\% chromosome-wide level) was not identified in chicken QTL literature. The only QTL reported on this sexual chromosome was a QTL for glucose content, identified by Zhou et al. (2007). With the multitrait analyses, 3 new areas of interest for metabolic traits during the overfeeding phase appeared on LG2a, LG21, and with a lower likelihood, on LG14. On LG14 and LG21, chromosome areas appeared to be involved in the control of lipid metabolism downstream of the liver. On LG2a, the plQTL impacting plasma corticosterone concentration before stress and glucose content is consistent with the fact that corticosterone is involved in glucose metabolism.

The QTL results for metabolic traits published in chickens are very diverse. To our knowledge, there has been no report of a QTL for corticosterone response after a stress on GGA2, although Buitenhuis et al. (2003) detected their strongest significant QTL for severe feather pecking on GGA2 in a chicken F2 population established from a cross 
between 2 commercial lines of laying hens differing in their propensity to feather pecking. Usually, the corticosterone response to a given stress is considered to be associated with feather pecking behavior (Buitenhuis et al., 2003). For blood glucose content, the strongest QTL published are scattered over GGA2 and GGA7 (Zhou et al. (2007), in a broilerFayoumi cross) and GGA20 and GGA27 (Park et al. (2006), in a cross between low- and high-weight White Plymouth Rock). The latter authors had already detected a QTL for cholesterol concentrations on GGA20 (corresponding to APL21) and a QTL for plasma triglyceride content on GGA2.

Lastly, Nadaf et al. (2009) reported a QTL for plasma glucose with a genome-wide level of significance on GGA13 (orthologous chromosome of APL14). However, no triglyceride or cholesterol assay was performed in this study, making any comparison difficult. All of these results suggest that metabolic traits are regulated by a large number of QTL with small effects, and that it is therefore difficult to highlight areas of interests shared by ducks and chickens.

Finally, although the multitrait analysis performed with correlated traits revealed new QTL regions, that with co-localized QTL led to better dissection of the results previously obtained by single-trait analysis. Whatever the traits, this approach evidenced the 2 main traits contributing to the pleiotropic effect. It is interesting to note that the most significant likelihoods were obtained with a combination of 2 traits but never more than 2 .

Although growth traits have been shown to be very heritable (Marie-Etancelin et al., 2011), the scarcity of QTL obtained by single or multitrait analysis for these traits in relation to the number of recorded traits may be explained by a highly polygenic genetic determinism of growth and the absence of QTL with strong effects for this trait. In contrast, we hypothesized that the more complex traits such as glucose, cholesterol, and triglyceride content, for which the heritability is particularly weak at the beginning of the overfeeding period (Marie-Etancelin et al., 2011), depended on numerous small QTL. Even if we have obtained here a large number of QTL for liver and meat quality traits, we need to keep in mind that the high number of traits tested for QTL detection (a total of 1008 analyses computed for the single-trait approach and 366 computations for multitrait analysis) generates an increased risk of false positive QTL.

As this is the first QTL detection study to be performed, objectives of future work will be to increase the density of the genetic map with SNP markers to cover duck chromosomes $8,10,11$, and 12 , which are missing in the present analysis, and to complete the macrochromosomes 5, 6, and 9. We also plan to refine the map for QTL affecting traits related to fatty liver quality, which should be studied as a priority because of their economic importance and the complexity of their measures.

\section{LITERATURE CITED}

Ambo, M., A. S. Moura, M. C. Ledur, L. F. Pinto, E. E. Baron, D. C. Ruy, K. Nones, R. L. Campos, C. Boschiero, D. W. Burt, L. L. Coutinho. 2009. Quantitative trait loci for performance traits in a broiler $\times$ layer cross. Anim. Genet. 40:200-208.

Atzmon, G., S. Blum, M. Feldman, A. Cahaner, U. Lavi, and J. Hillel. 2008. QTL detected in a multigenerational resource chicken population. J. Hered. 99:528-538.

Aulchenko, Y. S., D. J. de Koning, and C. Haley. 2007. Genomewide rapid association using mixed model and regression: A fast and simple method for genomewide pedigree-based quantitative trait loci association analysis. Genetics 177:577-585.

Buitenhuis, A. J., T. B. Rodenburg, Y. M. van Hierden, M. Siwek, S. J. B. Cornelissen, M. G. B. Nieuwland, R. P. M. A. Crooijmans, M. A. M. Groenen, P. Koene, S. M. Korte, H. Bovenhuis, and J. J. van der Poel. 2003. Mapping quantitative trait loci affecting feather pecking behavior and stress response in laying hens. Poult. Sci. 82:1215-1222.

Churchill, G., and R. Doerge. 1994. Empirical threshold values for quantitative trait mapping. Genetics 138:963-971.

Crooks, L., G. Sahana, D. J. de Koning, M. Lund, and O. Carlborg. 2009. Comparison of analyses of the QTLMAS XII common dataset. II: Genome-wide association and fine mapping. BMC Proc. 3(Suppl.1):S2.

Elsen, J. M., B. Mangin, B. Goffinet, D. Boichard, and P. Le Roy. 1999. Alternative models for QTL detection in livestock. I. General introduction. Genet. Sel. Evol. 31:213-224.

Filangi, O., C. Moreno, H. Gilbert, A. Legarra, P. Le Roy, and J. M. Elsen. 2010. QTLMap, a software for QTL detection in outbred populations. Com. 0787. Proc. 9th World Congr. Genet. Appl. Livest. Prod., Leipzig, Germany.

Fillon, V., M. Vignoles, R. P. Crooijmans, M. A. Groenen, R. Zoorob, and A. Vignal. 2007. Fish mapping of 57 bac clones reveals strong conservation of synteny between galliformes and anseriformes. Anim. Genet. 38:303-307.

Gao, Y., Z. Q. Du, W. H. Wei, X. J. Yu, X. M. Deng, C. G. Feng, J. Fei, J. D. Feng, N. Li, and X. X. Hu. 2009. Mapping quantitative trait loci regulating chicken body composition traits. Anim. Genet. 40:952-954.

Gilbert, H., and P. Le Roy. 2003. Comparison of three multi-trait methods for QTL detection. Genet. Sel. Evol. 35:281-304.

Gilbert, H., P. Le Roy, C. Moreno, D. Robelin, and J. M. Elsen. 2008. QTLMAP, a software for QTL detection in outbred population. Ann. Hum. Genet. 72:694.

Goffinet, B., P. Le Roy, D. Boichard, J. M. Elsen, and B. Mangin. 1999. Alternative models for QTL detection in livestock. III. Heteroskedastic model and models corresponding to several distributions of the QTL effect. Genet. Sel. Evol. 31:341-350.

Green, P., K. Falls, and S. Crooks. 1990. Documentation for CRIMAP. v. 2.4. Washington Univ. School of Medicine, St Louis, MO.

Hu, Z. L., C. A. Park, E. R. Fritz, and J. M. Reecy. 2010. QTLdb: A comprehensive database tool building bridges between genotypes and phenotypes. Invited paper 17. In: Proc. 9th World Congr. Genet. Appl. Livest. Prod., Leipzig, Germany.

Huang, Y., C. S. Haley, S. Hu, J. Hao, C. Wu, and N. Li. 2007b. Detection of quantitative trait loci for body weights and conformation traits in Beijing ducks. Anim. Genet. 38:525-526.

Huang, Y., C. S. Haley, F. Wu, S. Hu, J. Hao, C. Wu, and N. Li. 2007a. Genetic mapping of quantitative trait loci affecting carcass and meat quality traits in Beijing ducks (Anas platyrhynchos). Anim. Genet. 38:114-119.

Kileh-Wais, M., and J. M. Elsen. 2012. QTL detection from regression analysis of "generalized de-regressed proof" information. J. Anim. Breed. Genet. 129:336-342.

Knott, S. A., J. M. Elsen, and C.S. Haley. 1996. Methods for multiple marker mapping of quantitative trait loci in half-sib populations. Theor. Appl. Genet. 93:71-80.

Lander, E. S., and D. Botstein. 1989. Mapping Mendelian factors underlying 
quantitative traits using RFLP linkage maps. Genetics 121:185-199.

Lillehammer, M., B. J. Hayes, T. H. E. Meuwissen, and M. E. Goddard. 2009. Gene by environment interactions for production traits in Australian dairy cattle. J. Dairy Sci. 92:4008-4017.

Marie-Etancelin, C., B. Basso, S. Davail, K. Gontier, X. Fernandez, Z. G. Vitezica, D. Bastianelli, E. Baéza, M. D. Bernadet, G. Guy, J. M. Brun, and A. Legarra. 2011. Genetic parameters of product quality and hepatic metabolism in fattened mule ducks. J. Anim. Sci. 89(3):669679.

Marie-Etancelin, C., H. Chapuis, J. M. Brun, C. Larzul, M. M. Richard, and R. Rouvier. 2008. Genetics and selection of mule ducks in France: A review. World Poult. Sci. J. 64:187-207.

Marie-Etancelin, C., K. Feve, C. Genet, G. Cardinet, F. Vignoles, F. Pitel, and A. Vignal. 2006. Microsatellite DNA markers for duck (Anas platyrhynchos and Cairina moschata). Symp. Scientific Cooperation in Agriculture between COA (Tainan) and INRA (France) Taiwan. p. $165-168$.

Maruyama, K., M. K. Akbar, and C. M. Turk. 1999. Growth pattern and carcase development in male ducks selected for growth rate. Br. Poult. Sci. 40:233-239.

Maruyama, K., B. Vinyard, M. K. Akbar, D. J. Shafer, and C. M. Turk. 2001. Growth curve analyses in selected duck lines. Br. Poult. Sci. 42:574-582.

McRae, A. F., S. C. Bishop, G. A. Walling, A. D. Wilson, and P. M. Visscher. 2005. Mapping of multiple quantitative trait loci for growth and carcass traits in a complex commercial sheep pedigree. Anim. Sci. 80:135-141.

Nadaf, J., H. Gilbert, F. Pitel, C. Berri, K. Feve, C. Beaumont, M. Duclos, A. Vignal, T. E. Porter, J. Simon, S. E. Aggrey, L. A. Cogburn, and E. Le Bihan-Duval. 2007. Identification of QTL controlling meat quality traits in an F2 cross between two chicken lines selected for either low or high growth rate. BMC Genomics 8:155-162.

Nadaf, J., F. Pitel, H. Gilbert, M. J. Duclos, F. Vignoles, C. Beaumont, A. Vignal, T. E. Porter, L. A. Cogburn, S. E. Aggrey, J. Simon, and E. Le Bihan-Duval. 2009. QTL for several metabolic traits map to loci controlling growth and body composition in an F2 intercross between high- and low-growth chicken lines. Physiol. Genomics 38:241-249.

Park, H. B., L. Jacobsson, P. Wahlberg, P. B. Siegel, and L. Andersson. 2006. QTL analysis of body composition and metabolic traits in an intercross between lines divergently selected for growth. Physiol. Genomics 25:216-223.

Roldan, D. L., A. M. Dodero, F. Bidinost, H. R. Taddeo, D. Allain, M. A. Poli, and J. M. Elsen. 2010. Merino sheep: A further look at quantitative trait loci for wool production. Animal 4:1330-1340.

Rouvier, R., G. Guy, D. Rousselot-Paillet, and B. Poujardieu. 1994. Genetic parameters from factorial cross breeding in two duck strains (Anas platyrhyncos) Brown Tsaiya and Pekin, for growth and fatty liver traits. Br. Poult. Sci. 35:509-517.

Siwek, M., S. J. Cornelissen, A. J. Buitenhuis, M. G. Nieuwland, H. Bovenhuis, R. P. Crooijmans, M. A. Groenen, H. K. Parmentier, and J. J. van der Poel. 2004. Quantitative trait loci for body weight in layers differ from quantitative trait loci specific for antibody responses to sheep red blood cells. Poult. Sci. 83:853-861.

Skinner, B. M., L. B. W. Robertson, H. G. Tempest, E. J. Langley, D. Ioannou, K. E. Fowler, R. P. M. A. Crooijmans, A. D. Hall, D. K. Griffin, and M. Völker. 2009. Comparative genomics in chicken and Pekin duck using FISH mapping and microarray analysis. BMC Genomics 10:357-367.

Théron, L., X. Fernandez, N. Marty-Gasset, C. Pichereaux, M. Rossignol, C. Chambon, D. Viala, T. Astruc, and C. Molette. 2011. Identification by proteomic analysis of early post mortem markers involved in the variability in fat loss during cooking of mule duck 'foie gras'. J. Agric. Food Chem. 59:12617-12628.

Vitezica, Z. G., C. Marie-Etancelin, M. D. Bernadet, X. Fernandez, and C. Robert-Granie. 2010. Comparison of nonlinear and spline regression models for describing mule duck growth curves. Poult. Sci. 89:17781784.

Wahlberg, P., O. Carlborg, M. Foglio, X. Tortoir, A. C. Syvänen, M. Lathrop, I. G. Gut, P. B. Siegel, and L. Andersson. 2009. Genetic analysis of an $\mathrm{F}_{2}$ intercross between two chicken lines divergently selected for bodyweight. BMC Genomics 10:248-260.

Weller, J. L., Y. Kashi, and M. Soller. 1990. Power of daughter and granddaughter designs for determining linkage between marker loci and quantitative trait loci in dairy cattle. J. Dairy Sci. 73:2525-2537.

Wright, D., S. Kerje, K. Lundström, J. Babol, K. Schütz, P. Jensen, and L. Andersson. 2006. Quantitative trait loci analysis of egg and meat production traits in a red junglefowl $\times$ white leghorn cross. Anim. Genet. 37:529-534.

Ye, M. H., J. L. Chen, G. P. Zhao, M. Q. Zheng, and J. Wen. 2010. Associations of A-FABP and H-FABP markers with the content of intramuscular fat in Beijing-You Chicken. Anim. Biotech. 21:14-24.

Zhou, H., C. M. Evock-Clover, J. P. McMurtry, C. M. Ashwell, and S. J. Lamont. 2007. Genome-wide linkage analysis to identify chromosomal regions affecting phenotypic traits in the chicken. IV. Metabolic traits. Poult. Sci. 86:267-276.

\section{APPENDICES}

NOTE: Appendices 2 through 4 can be found along with the online version of the article, as Supplementary Material (http://journalofanimalscience.org).

Appendix 1. Mule duck zootechnical schedule

\footnotetext{
$\overline{\text { Growing } \quad \text { Mule ducks were fed ad libitum from } 0 \text { to } 6 \text { wk of age with a starting diet }(2820 \text { kcal ME/kg and 17.5\% CP) and then were feed-restricted from } 6 \text { to }}$ period $10 \mathrm{wk}$ of age $(230 \mathrm{~g} /$ day with a growing diet, $2850 \mathrm{kcal} \mathrm{ME} / \mathrm{kg}$ and $15.5 \% \mathrm{CP})$. With the same growing diet, the "pre-overfeeding" period started at 10 wk of age with $5 \mathrm{~d}$ of restriction $(200 \mathrm{~g} / \mathrm{d}$ ) and $6 \mathrm{~d}$ of gradual increase of the amount of feed (from $220 \mathrm{to} 320 \mathrm{~g} / \mathrm{j}$ ).

Overfeeding Animals were bred in collective cages of 4 or 5 individuals and were overfed twice a day with a mix of $35 \%$ corn flour, $25 \%$ corn grain, and period $\quad 40 \%$ water. The average amount of feed ingested by animal and by meal varied from $410 \mathrm{~g}$ (at the first meal of the overfeeding period) to $825 \mathrm{~g}$ (at the last meal).

At slaughter Animals were bled after "head-only" electrical stunning and plucked. The carcasses were refrigerated $24 \mathrm{~h}$ at $4^{\circ} \mathrm{C}$. Then, they were eviscerated and fatty liver, breast muscles, legs and abdominal fat were removed.
} 
Appendix 5. Detection of QTL for growth traits by single-trait analysis with $P$-values ranging from 1 to $5 \%$ of the chromosome-wide significance level

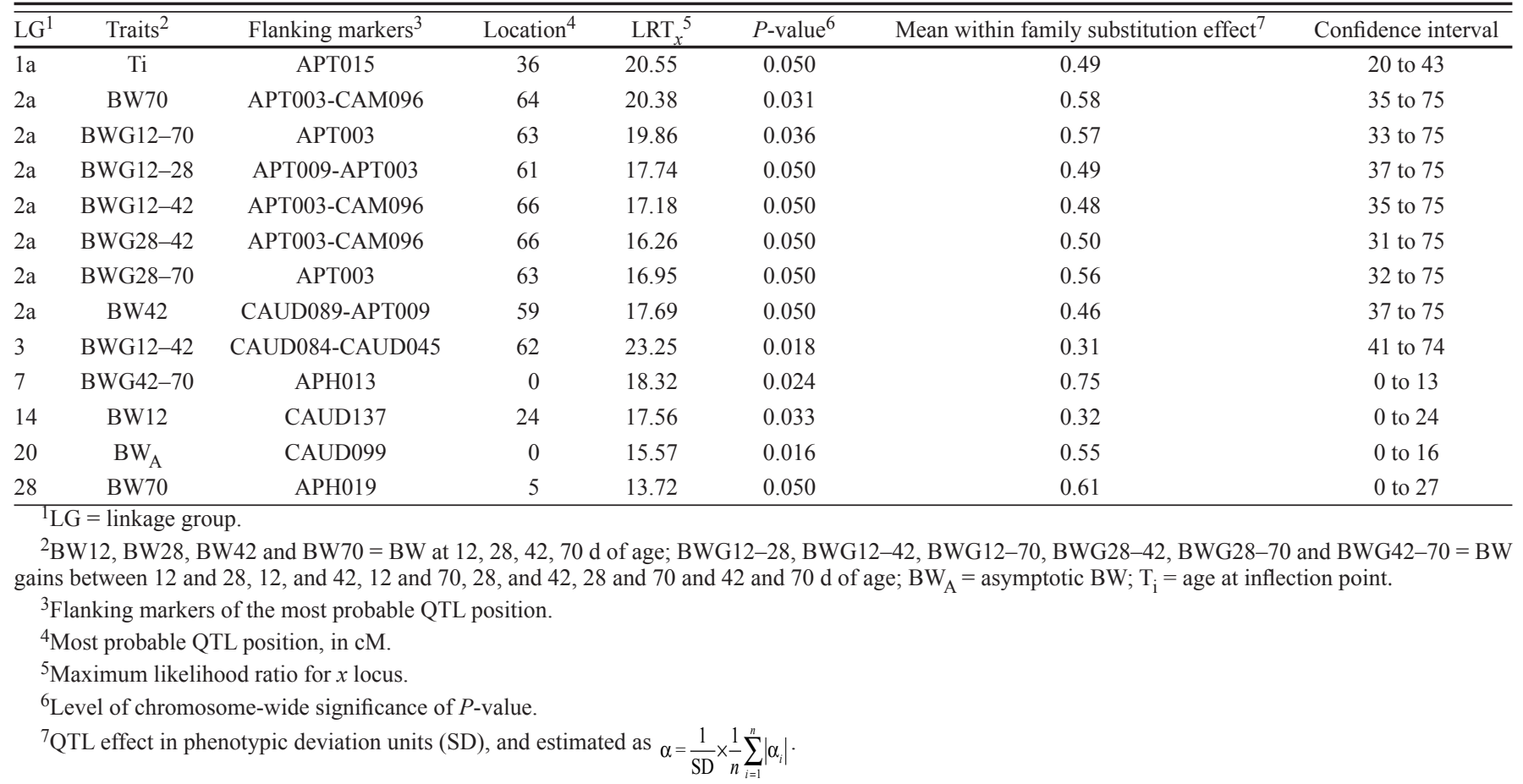

Appendix 6. Detection of QTL for metabolic and BW traits during the overfeeding phase by single-trait analysis with $P$-values ranging from 1 to $5 \%$ of the chromosome-wide significance level

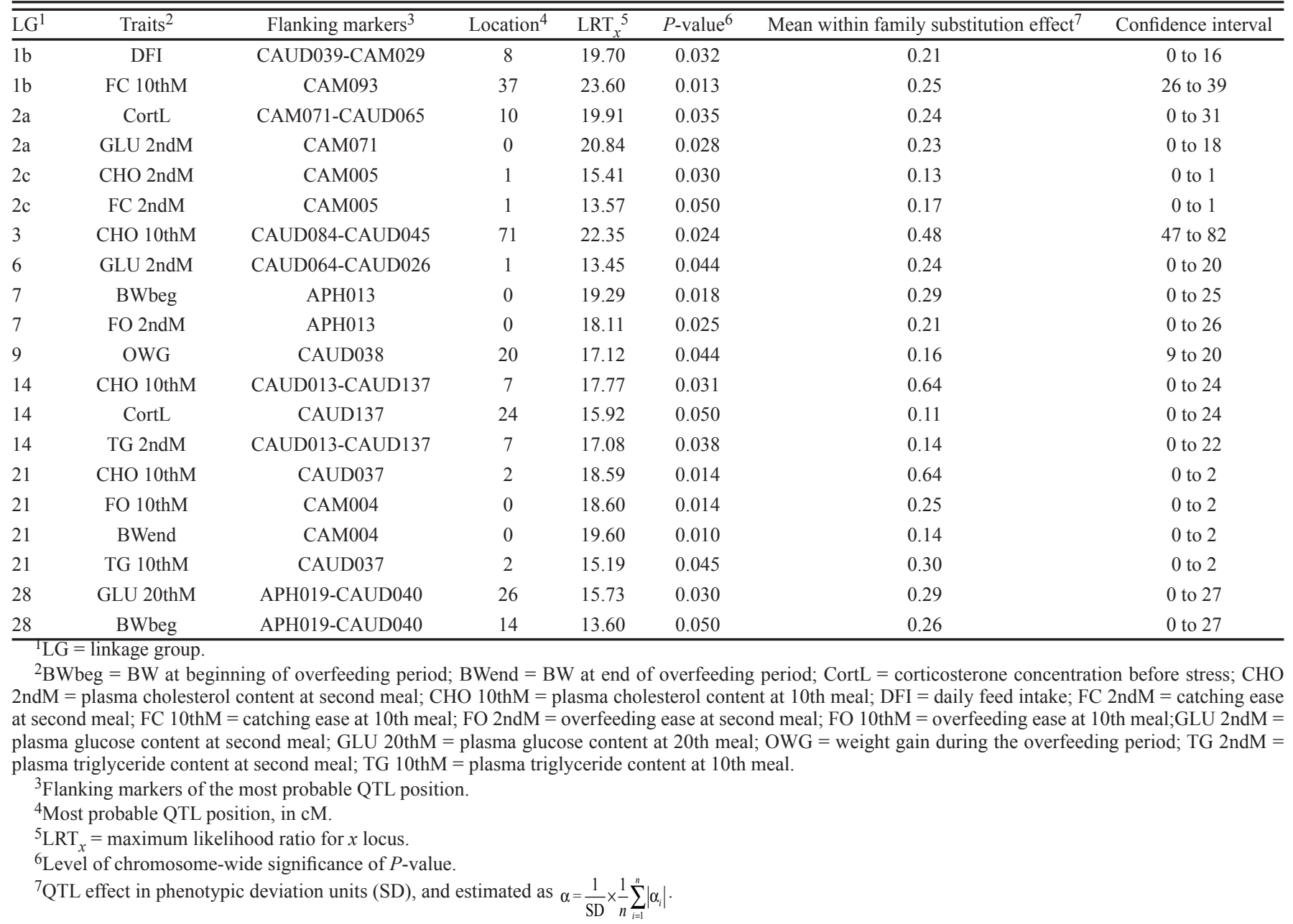


Appendix 7. The QTL detection for overfeeding ability and product quality traits by single-trait analysis with $P$-values ranging from 1 to $5 \%$ of the chromosome-wide significance level

\begin{tabular}{|c|c|c|c|c|c|c|c|}
\hline$\overline{\mathrm{LG}^{1}}$ & Traits $^{2}$ & Flanking markers ${ }^{3}$ & Location $^{4}$ & $\mathrm{LRT}_{x}^{5}$ & $P$-value ${ }^{6}$ & Mean within family substitution effect ${ }^{7}$ & Confidence interval \\
\hline $1 \mathrm{a}$ & $\mathrm{Lb}^{*}$ & APT008-CAUD058 & 55 & 21.77 & 0.037 & 0.15 & 50 to 89 \\
\hline 1a & MLipC & CAUD095 & 0 & 20.35 & 0.050 & 0.08 & 0 to 5 \\
\hline $2 \mathrm{a}$ & $\mathrm{La}^{*}$ & CAM071-CAUD065 & 2 & 19.64 & 0.038 & 0.28 & 0 to 27 \\
\hline $2 \mathrm{a}$ & $\mathrm{Mb}^{*}$ & CAM071-CAUD065 & 6 & 19.56 & 0.039 & 0.24 & 0 to 27 \\
\hline $2 \mathrm{a}$ & pmMW & APT002-CAUD070 & 40 & 21.27 & 0.025 & 0.16 & 37 to 49 \\
\hline $2 \mathrm{c}$ & $\mathrm{Lb}^{*}$ & CAM005 & 1 & 14.53 & 0.029 & 0.15 & 0 to 1 \\
\hline $2 \mathrm{c}$ & $\mathrm{MpHu}$ & CAM005 & 1 & 14.92 & 0.037 & 0.10 & 0 to 1 \\
\hline 3 & $\mathrm{Lb}^{*}$ & AMU060-CAM124 & 2 & 21.26 & 0.033 & 0.11 & 0 to 17 \\
\hline 6 & $\mathrm{MpH} 20$ & CAUD064-CAUD026 & 15 & 13.31 & 0.046 & 0.24 & 0 to 25 \\
\hline 7 & Ma* & AMU103 & 31 & 15.34 & 0.050 & 0.02 & 20 to 31 \\
\hline 7 & $\mathrm{MpH} 20$ & APH013 & 0 & 18.56 & 0.022 & 0.22 & 0 to 13 \\
\hline 21 & LColC & AMU111 & 1 & 16.48 & 0.030 & 0.16 & 0 to 2 \\
\hline 21 & Fmax & CAUD037 & 2 & 15.25 & 0.045 & 0.01 & 0 to 2 \\
\hline Z & $\mathrm{MpHu}$ & CAM113 & 15 & 20.44 & 0.019 & 0.01 & 9 to 15 \\
\hline
\end{tabular}

${ }^{1} \mathrm{LG}=$ linkage group.

${ }^{2} \mathrm{Fmax}=$ maximal shear force La* $=$ liver redness $; \mathrm{Lb}^{*}=$ liver yellowness LColC $=$ liver collagen content LL* = liver lightness; $\mathrm{LLipC}=$ liver lipid content; $\mathrm{Ma}^{*}=$ muscle redness; $\mathrm{Mb}^{*}=$ muscle yellowness; $\mathrm{MLipC}=$ muscle lipid content; $\mathrm{MpH} 20=$ muscle $\mathrm{pH} 20$ min post mortem; $\mathrm{MpHu}=$ muscle ultimate $\mathrm{pH} ; \mathrm{MR}=$ liver melting rate; $\mathrm{pmMW}=$ pectoralis major muscle weight.

${ }^{3}$ Flanking markers of the most probable QTL position.

${ }^{4}$ Most probable QTL position, in $\mathrm{cM}$.

${ }^{5} \mathrm{LRT}_{x}=$ maximum likelihood ratio for $x$ locus.

${ }^{6}$ Level ofchromosome-wide significance of $P$-value.

${ }^{7}$ QTL effect in phenotypic deviation units (SD), and estimated as $\alpha=\frac{1}{\mathrm{SD}} \times \frac{1}{n} \sum_{i=1}^{n}\left|\alpha_{i}\right|$. 
References

This article cites 37 articles, 11 of which you can access for free at: http://www.journalofanimalscience.org/content/91/2/588\#BIBL 